\title{
LA EPISTEMOLOGÍA \\ DE LA ESCUELA AUSTRIACA \\ DE ECONOMÍA \\ (LA FUNDAMENTAL APORTACIÓN \\ DE F. A. HAYEK \\ A LA TEORÍA DEL CONOCIMIENTO)
}

\author{
CÉSAR MARTÍNEZ MESEGUER*
}

Fecha de recepción: 13 de mayo de 2016

Fecha de aceptación: 3 de octubre de 2016

Resumen: El proceso exacto de formación y desarrollo del cerebro humano y de la mente es todavía en muchos aspectos un auténtico misterio. No obstante, parece claro que el proceso evolutivo permitió ir pasando desde los aspectos más básicos e instintivos, hasta niveles cada vez más elevados de abstracción, que permitieron la generación de habilidades complejas y de un lenguaje cada vez más elaborado. Pero ¿̇cómo creemos que funciona la mente humana? ¿ Cómo somos capaces de adquirir conocimientos y transmitirlos? ¿ Cuáles son los métodos adecuados para tratar de acercarnos a la «verdad» del mundo que nos rodea? Sobre estas materias, la Escuela Austriaca de Economía, ha realizado aportaciones muy interesantes, tanto en epistemología, como en metodología de las ciencias sociales, fundamentalmente gracias a la contribución de su representante más destacado, F. A. Hayek. El objetivo principal de este trabajo es tratar de dar a conocer la gran importancia de esa contribución, así como las consecuencias que de ella se derivan para la epistemología y la metodología de las ciencias sociales en general, y para la Economía y el Derecho en particular.

Palabras clave: Epistemología, evolutivo, metodología, ontología, conocimiento, ciencia, modelo, razón, Escuela Austriaca.

\footnotetext{
* Doctor en Derecho, profesor de la asignatura de Economía y Evolución del Master de Economía Austriaca de la Universidad Rey Juan Carlos de Madrid y de la asignatura de Introducción a la Economía en el Instituto de Estudios Bursátiles (IEB). Blog: martinezmeseguerblog.wordpress.com. Correo: cesar.m.meseguer@hotmail.com
} 
Clasificación JEL: B40, B41, B49, B52, B53.

Abstract: The exact process of the human brain and mind information and development is still, in many ways, a true mystery. Nonetheless, it seems clear that the evolutionary process enabled the brain and mind to progress from the most basic and instinctive aspects to evermore advanced levels of abstraction, which permitted the generation of increasingly complex abilities and elaborate language. But, how do we believe that the human mind works? How are we able to acquire knowledge and to transmit it? What are the appropriate methods to try and get close to the «real» world that surrounds us? The Austrian School of Economics has made some very interesting contributions to this subject, not only with regards to epistemology but also in the social sciences, mainly thanks to the contribution of the school's most outstanding representative, F.A. Hayek. The main goal of the present work is to try and make the importance of Hayek's contribution known, as well as to examine its derived consequences for epistemology and social science methodologies in general, and the consequences for Economics and Law in particular.

Key Words: Epistemology, evolution, methodology, ontology, knowledge, science, method, reason, Austrian School.

JEL Classification: B40, B41, B49, B52, B53.

\section{I \\ INTRODUCCIÓN}

Las aportaciones que desde la Escuela Austriaca de Economía (EAE) se han hecho, tanto a la ciencia económica, como a la jurídica o a la ciencia política, van siendo cada vez más conocidas por la mayoría de los especialistas, y lo mismo sucede con sus importantes y revolucionarias aportaciones en lo que se refiere a metodología: el subjetivismo, el marginalismo, la Teoría de la acción humana, la Teoría de la función empresarial, la Teoría de las instituciones sociales evolutivas, etc. Sin embargo, otras aportaciones efectuadas por algunos de sus autores, resultan todavía prácticamente desconocidas, este es el caso de los trabajos efectuados por F.A. Hayek respecto de la epistemología y la teoría del conocimiento. El presente trabajo tiene como objetivo principal hacer un análisis sobre cuales fueron sus contri- 
buciones más destacadas en dicha materia, comenzando con sus investigaciones sobre el funcionamiento de la mente humana, que se encuentran más relacionadas con la psicología y la neurociencia, y terminando con sus conclusiones ya puramente filosóficas, pero de trascendental importancia para comprender como entendía Hayek que debía ser la labor de cualquier científico y, más aún, la del estudioso de las ciencias sociales, con todas las repercusiones que ello tiene respecto de los posibles planteamientos metodológicos, la elaboración de teorías y modelos, etc. También veremos como todas sus investigaciones y estudios le llevaron siempre a defender lo que él denominaba el racionalismo moderado (prudente y basado en la modestia intelectual), conocedor de los límites de la razón y de la mente humana, frente al racionalismo exagerado que atribuye a la razón cualidades y propiedades que en realidad no tiene. Finalmente veremos también como se puede relacionar e integrar el pensamiento de Hayek con el de otro de los grandes autores de la EAE como es L. von Mises, así como la influencia mutua que se produjo entre Hayek y Popper, y el resto de filósofos pertenecientes a la corriente de pensamiento denominada Epistemología evolutiva. Con todo ello trataremos de lanzar un poco de luz sobre todas estas materias que, como ya hemos dicho al comenzar la presente introducción, no han sido del todo desarrolladas en profundidad, y sobre las que todavía hay mucho desconocimiento e interpretaciones erróneas.

\section{II SENSACIÓN Y PERCEPCIÓN}

Cuando se realiza un análisis de temas tan complejos como los que vamos a tratar en las siguientes líneas (es decir, cuando tratamos de hallar respuestas a preguntas como: qué es la mente y cómo funciona, cómo adquirimos nuestro conocimiento y cómo lo transmitimos, etc.), siempre es conveniente partir de los aspectos más básicos, para ir poco a poco viendo como se desarrolla todo el entramado posterior de conocimientos y teorías cada vez más elaboradas ${ }^{1}$. Por ello,

\footnotetext{
${ }^{1}$ No obstante, partiremos del ser humano tal y como es hoy, siendo conscientes de la existencia previa de toda una serie de procesos evolutivos, tanto biológicos como
} 
comenzaremos por tratar de comprender y definir qué son las sensaciones y las percepciones, campo en el que F. A. Hayek hizo una serie de aportaciones fundamentales para la explicación de los fenómenos mentales, introduciendo un análisis dinámico-evolutivo, y aportando, finalmente, una serie de teorías muy interesantes sobre la interacción de las sensaciones, las percepciones, la memoria y la consciencia.

Las sensaciones podrían definirse como los datos proporcionados por los sentidos a nuestro cerebro, mientras que la percepción, como seguidamente veremos, es la facultad de clasificar dichas sensaciones. Esta primera etapa de clasificación, da lugar a un complicado proceso que continúa al dar un sentido, un significado $\mathrm{y}$, posteriormente, un nombre a las sensaciones; atribuyendo, igualmente, patrones y propiedades, tanto a los objetos identificados gracias a la clasificación efectuada, como a las relaciones descubiertas entre ello, y/o bien al clasificar sencillamente como bueno o malo lo que percibimos (aspecto este de trascendental importancia, tal y como más adelante explicaremos y que tiene especial relevancia en la formación del lenguaje, las normas morales y el derecho).

Lamentablemente, sabemos a ciencia cierta que las sensaciones no proporcionan al sujeto una información concreta y exacta de lo que son las cosas, sino que, a lo sumo, le dicen algo acerca de determinadas cualidades detectadas en ellas por nuestros sentidos ${ }^{2}$. Cu-

culturales, complejamente interrelacionados, que nos han traído hasta nuestros días, y gracias a los cuales disponemos de nuestro cerebro, entendido como soporte a través del cual nuestra mente puede desarrollar todas sus capacidades.

2 A este respecto resulta muy curioso estudiar las aportaciones efectuadas por la biología y la zoología respecto de las diferencias existentes entre los sistemas sensoriales observados en el reino animal y los sentidos de los que dispone un ser humano. Muchos sentidos animales, no es que sean mejores o más potentes y precisos que los nuestros, que lo son en muchos casos, sino que en ocasiones son totalmente distintos, apareciendo ante nuestros ojos como si se tratase de auténticos «superpoderes» de héroes de cómic, como son los casos de: la detección de determinados componentes químicos para nosotros inapreciables, la visión de espectros de color diferentes a los nuestros, la ecolocalización, la orientación y localización de presas a través de la detección de campos electromagnéticos, etc. Todo ello nos lleva a poder afirmar que, sin necesidad de avanzar más en el estudio de la teoría del conocimiento, nos damos cuenta de que, dependiendo de que se posean unos sentidos u otros, o de lo desarrollados que estén, la visión del mundo que nos rodea puede cambiar radicalmente. 
riosamente, las sensaciones son algo totalmente diferente de lo que el ser humano interpreta, es decir, la imagen visual, sonora, etc. que llega al cerebro, implica que lo que sentimos (lo que vemos, oímos, etc.), sea diferente de lo que percibimos y que, en la mayoría de las ocasiones, lo que percibimos sea realmente fruto, en gran medida, de un proceso de aprendizaje, ya que aprendemos a percibir y a reconocer objetos y relaciones entre ellos, pues nuestros sentidos sólo nos proporcionan una información incompleta de los mismos. Es decir, las características observadas en los objetos no son sólo fruto de los estímulos físicos, ni de las consiguientes reacciones neurofisiológicas, sino que dependen también de la propia experiencia pasada del sujeto que se mantiene almacenada en su memoria. De esta manera habría, por tanto, unas percepciones que provocarían reacciones inmediatas, espontáneas, etc. y otras fruto del aprendizaje (pudiendo combinarse y fusionarse ambas categorías de forma muy compleja). Además, debe tenerse en cuenta, que todo el proceso de la percepción es selectivo, ya que unas veces de forma inconsciente y otras de forma consciente (en ocasiones incluso de forma sesgada por intereses personales), se selecciona de entre una infinidad de cosas sólo algunas concretas. Y dicha selección (tanto la inconsciente como la consciente) es, en realidad, una especie de defensa frente a la ingente y casi infinita cascada de información que llegaría hasta nosotros y que colapsaría con total seguridad a nuestro cerebro.

Partiendo de esto, nos damos cuenta de que ya en las primeras fases de adquisición de información por parte de nuestro cerebro, comienzan a producirse toda una avalancha de posibles fallos y errores, muchos de los cuales desconocemos, por lo que escapan a nuestro control y posible corrección. Dichos errores los iremos mencionando a lo largo del presente trabajo, comenzando por los errores introducidos por los sentidos al preseleccionarse determinados estímulos y los errores introducidos por la propia limitada capacidad de nuestros sentidos para poder captar estímulos correctamente y con la máxima efectividad (estímulos, por otra parte, ya discriminados previamente).

El análisis de la sucesiva generación de errores en los procesos de adquisición de conocimiento es de radical importancia, ya que dichos procesos jamás se dan limpios de imperfecciones y de forma 
aislada o separada, sino dentro de complejísimos entramados de influencia e interrelación mutua de todos los elementos que lo integran y a todos los niveles, lo que dificulta mucho su estudio, provocando que desconozcamos su alcance y sus consecuencias.

Retomando los aspectos que estamos analizando, podemos afirmar que, en este punto, la principal aportación de Hayek se encuentra perfectamente resumida por el profesor Joaquín M. Fuster en el prólogo que hace a la obra de aquél, titulada El orden sensorial, donde manifiesta la relevancia, la gran importancia y el poder que tienen la combinación entre sensaciones:

En la nueva psicología de la percepción que él propone, no hay sensaciones elementales ni núcleos de sensación á la Mach. Todas las percepciones, aún las más elementales, se basan en las relaciones de contigüidad o simultaneidad entre los estímulos o impulsos a que ha estado sujeto el organismo en su propio pasado o en el pasado de la especie. Ahí es donde Hayek encuentra el fulcro para su giro copernicano: en la evolución de la especie y del individuo, a saber, en la filogenia y en la ontogenia. No hay nada nuevo en el mundo de los sentidos. Todo lo que sentimos y percibimos es de carácter asociativo, es el conjunto de relaciones que se han formado entre estímulos que han ocurrido al mismo tiempo y en los mismos lugares en la historia de la especie o del organismo individual. A los niveles más bajos, las sensaciones primarias se basan en relaciones entre estímulos simples que en el curso de la evolución han establecido relaciones de contigüidad o continuidad espacial o temporal. Así es como se forman los receptores sensoriales y las estructuras sensoriales primarias de tálamo óptico y de la corteza cerebral. Esas estructuras constituyen, por así decirlo, la memoria de la especie, la memoria filética o evolutiva, la cual se formó en «la noche de los tiempos» para mejor adaptar la especie a las vicisitudes del medio ambiente. Por encima de aquellos niveles más bajos del orden sensorial, presumiblemente en la llamada corteza de asociación, se van formando los sistemas de relaciones entre estímulos, digámoslo ya, las redes de la memoria perceptiva individual (en el plano psicológico, Hayek las llama mapas) que almacenan en su estructura la memoria del individuo, plásticas, dinámicas y abiertas al futuro, sujetas a cambio constante hasta la muerte. ${ }^{3}$

${ }^{3}$ Extracto del prólogo realizado por Joaquín M. Fuster a la obra de F. A. Hayek titulada El orden sensorial, que referenciamos en la bibliografía al final del presente 
El fruto de esos dos tipos de evolución (especie-organismo individual) han determinado todos nuestros sistemas de adquisición de conocimiento, pudiendo afirmarse, tal y como fue expuesto por Hayek, que, en definitiva, percibir es, ni más ni menos, que clasificar el mundo en diferentes conjuntos de relaciones entre estímulos cuyas formas de percepción se han ido formando a lo largo de la evolución de cada especie y del propio organismo que percibe. De esta manera, las partes del sistema nervioso que tienen como función la percepción, son básicamente un instrumento clasificatorio de relaciones entre estímulos, mientras que la percepción de un objeto está definida por las relaciones entre los componentes sensoriales que de él se han captado. Curiosamente, esos componentes aislados no tienen una cualidad mental concreta, sino que es el conjunto el que la tiene. Así, confirmando esta importante aportación de Hayek, el profesor Fuster sostiene que se puede resolver, teóricamente, un problema que ha venido preocupando a los psicólogos desde hace mucho tiempo, y que no es otro que el problema de la constancia perceptiva, encontrándose la explicación en la propia relación y en el orden de los referidos componentes sensoriales. Es decir, el todo de cada percepción almacenada está definido por el orden y por las relaciones entre cada una de las partes, por lo que, a todos los niveles, la percepción consiste en un orden sensorial que se ha formado en el sistema nervioso por actos de clasificación del entorno, en los que intervienen tanto la evolución de la especie, como la evolución y desarrollo del individuo en sociedad. Encontrándose dotada de los dos atributos que fundamentalmente la conforman: el relacional y el evolutivo (a nivel filogenético y ontogénico).

Puede afirmarse que el concepto fundamental o núcleo de esta teoría es la idea de orden, ya que nos encontraríamos con que las propiedades estructurales y funcionales de un sistema biológico, derivarían de las relaciones entre sus componentes y no de las propiedades individuales de los mismos de forma aislada. El significado de una estructura y las funciones de un sistema residen en la

trabajo. Joaquín M. Fuster, como es bien sabido es doctor en filosofía y medicina, y es uno de los pioneros de la neurofisiología de la cognición más reconocidos a nivel mundial. 
ordenación de sus partes y son irreductibles a las mismas. Todo el orden sensorial y la percepción, se fundamentan en las relaciones entre elementos, más o menos complejos, y en su ordenación en forma de redes cognitivas. De esta manera, siendo los elementos importantes, lo son mucho más aún las relaciones entre ellos.

Según Hayek en el sistema nervioso, probablemente en la corteza cerebral, debía existir una organización estructural y funcional isomórfica con la organización de sus mapas y redes sensoriales, hecho éste que se ha ido confirmado con posterioridad gracias a los avances de la neurociencia cognitiva de finales del siglo $x x$ y primeros del xxI. Ya que es en la raíz biológica de este proceso dinámico de formación de redes - por el cual lo sensorial se convierte en mental- donde está la facilitación de contactos sinápticos entre neuronas. De esto se deriva, entre otras muchas cosas, que la mayor o menor inteligencia no dependa sólo del tamaño del cerebro o del número de neuronas, sino, también del número y la forma de las conexiones y redes neuronales.

Las redes cognitivas mantienen uniones ente sí y zonas comunes, por lo que un grupo de neuronas, prácticamente en cualquier lugar de la corteza, puede formar parte de muchas redes distintas y, por lo tanto, de muchas memorias. Hoy en día ya se sabe que las referidas redes o «mapas» neuronales que explican el orden sensorial en la mente humana, trascienden la percepción y la memoria. Según recientes investigaciones basadas en la neuro-imagen y la electro fisiología, permiten afirmar que a esas dos funciones hay que añadir la atención, la inteligencia y el leguaje. Es decir, que las cinco funciones cognitivas fundamentales son el resultado de la activación selectiva y ordenada, en el tiempo y en el espacio cerebral de las redes cognitivas que forman nuestro mundo interno y que interpretan, con todas sus limitaciones, nuestro mundo externo.

Lo cierto es que aunque nos parece que los objetos y las relaciones gozan entre ellos de un valor constante y de una especie de identidad propia (debido a los modelos organizativos de la percepción), lo cierto es que en muchos casos un mismo estímulo - «objetivamente» idéntico- provoca dos percepciones totalmente diferentes en dos sujetos, lo que hace pensar que la interpretación dentro del contexto perceptivo depende en gran parte de las expe- 
riencias previas del sujeto (sin olvidar que las peculiaridades fisiológicas de cada uno también influyen, así como el grado de atención, el interés personal, la experiencia pasada, etc.). Es decir, que existe una gran relación entre la forma particular de percibir la realidad que nos rodea y diversos y variados factores que se interrelacionan entre si, como: las experiencias vividas por cada uno de nosotros, las necesidades circunstanciales del momento (biológicas y culturales), la propia personalidad del sujeto, el entorno social, los estados emocionales, etc.

De esta manera, reconocer objetos y relaciones consiste en clasificarlos. Actividad esencial de la percepción que también se conoce con el nombre de categorización. Y decimos que se trata de una actividad esencial, ya que si no somos capaces de clasificar algo en base a todo el proceso descrito, no sería en realidad un objeto para nosotros, sino simplemente un montón informe y sin sentido de sensaciones. De aquí la gran influencia que para la percepción tiene también el fantástico instrumento que nos proporciona el lenguaje, el cual nos permite dar nombre a las categorías, facilitándonos el poder relacionarlas entre si. De esta manera, generamos también clasificaciones compartidas con otros individuos mediante convenciones que nos permiten comunicarnos y transmitir información (datos), lo que genera nuevos tipos de errores derivados de los propios procesos de clasificación de las percepciones. Pero sobre todo esto volveremos a hablar más adelante.

III

\section{LA NECESIDAD: LA MOTIVACIÓN PARA ACTUAR (EL COMPORTAMIENTO MECÁNICO Y LA ACCIÓN HUMANA CONSCIENTE)}

El desencadenante de todo comportamiento es siempre un estímulo percibido (percepción) que, o bien proviene del medio externo, o bien del medio interno del propio organismo. Y son precisamente los estados internos provocados por dichos dos tipos de estímulos los que generan necesidades (impulsos que buscan cambios en ciertos sentidos para superar alguna carencia sentida), que son las motivaciones que actúan como desencadenantes de acciones. Es 
decir, las necesidades y las motivaciones generadas por éstas, son los estados internos del organismo que actúan, por tanto, como desencadenantes de las acciones ${ }^{4}$. La necesidad y la motivación no son observables, ya que son subjetivas e internas, pero si se pueden deducir, en parte, del análisis de las reacciones que se dan entre las características del estímulo y el comportamiento desencadenado (acción). Esto genera otro tipo de errores derivados del estudio de ámbitos que en esencia pertenecen al mundo subjetivo de cada individuo y de los cuales no tenemos suficiente información.

Este esquema de la acción viene determinado en gran medida por nuestra herencia filogenética, tal como ya lo dijo L. von Mises en su obra La Acción Humana ${ }^{5}$ así como por la estructura heredada de nuestro sistema nervioso y, por ello, de nuestro cerebro humano, coincidiendo plenamente en este punto con las teorías que, tal y como ya hemos indicado, desarrolló Hayek. A la hora de referirse a la acción, Hayek deja bien claro en sus escritos que para diferenciar las respuestas puramente mecánicas frente a las intencionales, debe tenerse en cuenta que si bien en principio la transmisión de impulsos en el sistema nervioso central podría describirse como de tipo mecánico, sin embargo, el resultado de la interacción y asociación de dichas transmisiones en el sistema nervios integrado y organizado - según los principios que se han indicado- evidencia características que ya no pueden calificarse como meramente mecánicas, ya que el resultado de su propia actividad provoca cambios importantes de estructura, que pueden modificar las acciones que se efectúan, provocando que rara vez se responda con total exactitud a las mismas o similares condiciones del exterior. Debido precisamente a estas pautas (de las huellas dejadas por experiencias pasadas), se irá adquiriendo la capacidad de realizar acciones nuevas y/o diferentes. Por ello, dichas nuevas acciones ya no son meramente mecánicas, sino que serían auto-adaptativas, en el sentido de que vendrán determinadas no sólo de forma directa por las influencias externas, sino también por el estado de sus propios procesos internos, produciéndose un abanico mucho más am-

\footnotetext{
${ }^{4}$ Quedando claramente establecida la relación existente entre estímulo, necesidad, motivación y acción.

${ }^{5}$ Mises, L. (2007). La Acción Humana, pp. 111 ss.
} 
plio y cambiante de posibles respuestas. De esta manera, será la propia trayectoria cambiante del organismo la que empiece a determinar sus respuestas. Respuestas que podrán ir haciéndose cada vez más y más complejas, al poder irse ajustando intencionadamente a las cualidades de cada acción y a los diferentes sucesos del mundo exterior. En definitiva tendríamos, por una parte, unos comportamientos intencionales y adaptativos frente al exterior $y$, por otra parte, unos «modelos» del entorno formados por patrones de impulsos en el sistema nervioso, que representarán situaciones que pueden producirse en función de los datos obtenidos del exterior. Estaríamos ante procesos de clasificación por mapas (aparatos semi-permanentes de clasificación), que generan los modelos de situaciones concretas. Modelos que seleccionan elementos del entorno (estímulos) y los tratan como una clase de acontecimientos (serían «microcosmos» dentro del «cosmos»). Sobre esta especie de «microcosmos» sería sobre los que se basaría la predicción de cierta clase de acontecimientos que, si bien facilitarían la adaptación al entorno y la supervivencia - si son suficientemente correctos-, nunca se podrían calificar de "certezas universales o absolutas» debido a su propia naturaleza parcial, limitada y finita.

Sobre todo esto, Hayek nos hace las siguientes aclaraciones y advertencias, por la trascendencia que más adelante veremos que tienen, insistiendo en que lo que él denomina «mapas» no son una representación del mundo, sino que en realidad son una especie de teoría sobre como interpretamos que el mundo funciona. Siendo así, los modelos generados simplifican muchísimo las tareas que conlleva una adaptación con éxito al entorno, pero, al mismo tiempo tienen evidentes inconvenientes: los modelos están muy limitados para poder reproducir aspectos verdaderamente significativos de la realidad. No obstante, gracias a que la predicción de ciertas clases de sucesos es posible contando con una simple selección de la totalidad de eventos, se hace viable una adaptación intencionada. Todo ello implica, como contrapartida, que, al tener que escoger y simplificar los sucesos y relaciones que deben tenerse en cuenta para lograr los fines buscados por los actores, jamás se podrá alcanzar un tipo de información que pueda llegar a clasificarse de verdad universal o certeza absoluta salvo que estemos tomando (por necesidades prácticas, o por error), al microcosmos $-\mathrm{O}$ modelo-, 
como si se tratase del cosmos. En caso de ser ésta una elección científica debería advertirse con claridad y tomarse las debidas precauciones, teniendo mucho cuidado con las peligrosas conclusiones que puedan extraerse de esa licencia útil, en algunos casos, pero incorrecta.

De todo lo visto se desprende la posibilidad de que se generen nuevos errores en la correcta formación de modelos de sensaciones que representan el entorno de cada situación, así como errores en la correcta formación de mapas neuronales que permiten la orientación y posterior clasificación de los impulsos recibidos. Y, finalmente, errores en las formas de interrelación y mutua influencia entre modelos y mapas generados por las propias percepciones del momento y, a su vez, por los generados y almacenados a raíz de sensaciones y percepciones previas del individuo, que, además, se encuentran condicionadas por aspectos fisiológicos evolutivos de nuestra especie.

De lo que acabamos de ver se desprende que la combinación de mapas y modelos es la que genera, de forma prácticamente inevitable, comportamientos guiados que podrían «predecir» los resultados de las distintas acciones, seleccionando las que en principio se prevé que pueden generar resultados más satisfactorios. De esta manera, se comenzarían a realizar acciones deliberadas y proyectadas, en función de los resultados más satisfactorios esperados, capaces de colmar las necesidades sentidas subjetivamente de la forma más fácil y agradable para el actor (es decir: evitando malestar excesivo, dolor, buscando la menor resistencia, un esfuerzo menor, etc.). Sin embargo, todos estos procesos todavía no implican necesariamente lo que denominamos una consciencia plena.

Por su parte Mises define su modelo de acción humana — que se deriva de necesidades y motivaciones - de la siguiente manera:

La acción humana es una conducta consciente, movilizada voluntad transformada en actuación, que pretende alcanzar precisos fines y objetivos; es una reacción consciente del «ego» ante los estímulos y las circunstancias del ambiente; es una reflexiva acomodación a aquella disposición del universo que está influyendo en la vida del sujeto. ${ }^{6}$

${ }^{6}$ Op. cit., p. 15. 
Mises quiere establecer y deja clara la diferencia entre dicha acción consciente y la conducta inconsciente:

El proceder consciente y deliberado contrasta con la conducta inconsciente, es decir, con los reflejos o involuntarias reacciones de nuestras células y nervios ante las realidades externas.?

Sin embargo, la separación entre actos conscientes e inconscientes no es tan clara en muchos supuestos, y así lo planteó Hayek algunos años después, al manifestar que lo que en principio parece una evidente diferencia de clase entre respuestas claramente mecánicas y respuestas derivadas de procesos mentales más complejos, es más una distinción de grado que de clase:

La consciencia es evidentemente capaz de muchos grados diferentes de intensidad, y entre los estados claramente conscientes y los claramente inconscientes existen muchas formas de hechos semiconscientes con relación a los cuales es difícil decidir si pueden ser descritos como conscientes o no. ${ }^{8}$

Hayek añade, al referirse a qué debemos entender por procesos mentales conscientes, que resulta prácticamente imposible dar una definición que pueda ser generalmente aceptada y satisfactoria respecto de los mismos. No obstante, lo que si considera factible es tratar de comprender qué cosas hace la consciencia que la diferencian de los procesos mentales claramente inconscientes, como por ejemplo:

a) El hecho de saber subjetivamente que estamos controlando deliberadamente una acción (frente a aquellas que no somos plenamente conscientes de que las estamos, o no, controlando).

b) La existencia de casos extremos donde la diferencia entre un tipo y otro parece tan completa que casi podría hablarse de diferencia de clase.

c) Aquellos supuestos que al analizarlos entendamos que, si son procesos mentales conscientes, deberán contar, por ese motivo,

\footnotetext{
${ }^{7}$ Op. cit., p. 15.

${ }^{8}$ Hayek, F. A. (2004). El orden sensorial, p.p.231-232.
} 
con un grado especialmente alto de modificabilidad e intencionalidad (estando muy relacionados unos con otros y generando comportamientos completamente nuevos), etc. Características éstas que sin embargo son mucho más escasas en los procesos no conscientes.

Pero, todo ello, teniendo en cuenta que son simples procedimientos que sólo intentan aclarar determinados aspectos que ayuden a diferenciar entre acciones conscientes y acciones no conscientes.

Finalmente, Mises completa su concepto de acción humana añadiendo que:

El hombre, al actuar, aspira a sustituir un estado menos satisfactorio por otro mejor. La mente presenta al actor situaciones más gratas, que éste, mediante la acción, pretende alcanzar. Es siempre el malestar el incentivo que induce al individuo a actuar. ${ }^{9}$

Ahora bien, siendo esa nuestra base, o punto de partida, a la hora de hablar del esquema que nos lleva desde las sensaciones a la acción consciente ${ }^{10}$, debe tenerse en cuenta que cada cerebro tiene sus peculiaridades y características que contribuyen a nuestra diferenciación como individuos.

\footnotetext{
${ }_{9}$ Mises, L. La Acción Humana. Op. cit., p. 18.

${ }^{10}$ Fue precisamente el estudio de la acción consciente y racional desarrollada por el hombre, tal y como ya hemos mencionado, lo que centró el análisis de L. von Mises en su obra La Acción Humana, op. cit., siguiendo la investigación ya iniciada por Carl Menger años antes al desarrollar sus planteamientos metodológicos subjetivistas. Con posterioridad, esta metodología axiomático-deductiva, que parte de la Teoría de la acción, ha sido fundamental en muchos estudios posteriores de autores de la Escuela Austriaca, como es el caso de la obra del Profesor Israel M. Kirzner en Creatividad, Capitalismo y Justicia Distributiva (Madrid 1995), o en la del Profesor J. Huerta de Soto, Socialismo, cálculo económico y función empresarial, (Madrid 1992), etc.
} 


\section{MEMORIA: RECUERDO E IMAGINACIÓN}

El complemento imprescindible para la adquisición de conocimientos y conductas que conocemos como aprendizaje, es la posibilidad de reproducirlos, completarlos y actualizarlos. Para comprender todos estos procesos es necesario saber que existe una estrecha conexión entre percepción, memoria, recuerdo e imaginación, relación que abarca también al pensamiento y al lenguaje, ya que pensamos con conceptos referidos a cosas percibidas, imaginadas o recordadas. Mientras que la percepción sólo se produce cuando tenemos presente el estímulo que la provoca, la imaginación y la memoria se refieren a estímulos no presentes. La principal diferencia es que mientras que la memoria trabaja con sensaciones que necesariamente han sido percibidas en el pasado y son recordadas, la imaginación puede escaparse a esa realidad percibida, al tiempo y al espacio.

La imaginación se puede definir como la capacidad de evocar o reproducir percepciones previamente memorizadas — con mayor o menor distorsión. Puede apreciarse una distinción entre:

a) Imaginación reproductora (recuerdo): que reproduce imágenes referidas a percepciones concretas (cuyo extremo son las imágenes eidéticas que son prácticamente fotografías mentales).

b) Imaginación creadora: cuando de percepciones previas, que han generado modelos de la realidad, elaboramos formas nuevas que no se corresponden con dichos modelos.

c) Imaginación fantástica (fantasía): al irse alejando la imaginación de la realidad originariamente percibida, esta puede quedar muy deformada, dando lugar a «mundos» totalmente diferentes.

Por su parte la memoria es la capacidad de recordar, en otras palabras: la permanencia o retención de la experiencia percibida con anterioridad. De esta manera, la memoria referida estrictamente a la conducta sería la posibilidad de poner en práctica un hábito adquirido con anterioridad, sin necesidad de que se ensaye cada una de las fases de su desarrollo, mientras que la referida al 
conocimiento, que es la más habitual, es donde funciona la actividad psíquica llamada representación.

En la memoria pueden diferenciarse cuatro etapas: 1) fase previa de selección de información. Esta selección tiene dos etapas a las que ya nos hemos referido, una inconsciente y otra consciente que está íntimamente relacionada con la atención, ya que se trata de un añadido de la experiencia consciente que incrementa la selección típica de la consciencia. 2) La fijación de la información (en la que intervienen factores como la intensidad, duración, repetición y la novedad de lo aprendido; también aspectos psicológicos o emocionales; así como el componente lógico, donde adquiere radical importancia la organización lingüística). 3) La fase de conservación o almacenaje (uno de los aspectos más desconocidos y sobre los que existen diferentes teorías centradas en aspectos bioeléctricos, biomoleculares, etc.). Y, por último, 4) la fase de reproducción o actualización de la información (donde también se estudian diferentes modos de actualizar la información adquirida: reconocimiento, reproducción, memoria reintegrativa o el reaprendizaje, etc.).

Cada uno de estos aspectos vuelve a evidenciar la posible generación de nuevos tipos de errores como: los errores por pérdida de datos en almacenaje y reproducción, los errores de la selección y discriminación de datos, y los errores derivados de la consciencia y la atención.

\section{$\mathrm{V}$}

\section{APRENDIZAJE Y TRANSMISIÓN DE LA INFORMACIÓN ${ }^{11}$}

Para la psicología, el aprendizaje ${ }^{12}$, o proceso de adquisición de información, es decir, de conocimientos, habilidades, destrezas, valores, etc., es un cambio más o menos permanente de la forma en que

${ }^{11}$ Aquí ya entendida la información como datos procesados e interrelacionados que constituyen un mensaje que permite establecer cualidades y relaciones entre las cosas.

${ }^{12}$ En el campo del aprendizaje ha habido importantes aportaciones ya desde el siglo pasado, con las teorías del Condicionamiento clásico (Iván P. Pavlov), la del Condicionamiento operante (B.F. Skinner), o la del Aprendizaje por discernimiento, etc. 
comprendemos las cosas y desarrollamos nuestro comportamiento, que ocurre como resultado de la adquisición de nueva información o de reorganización de la que disponemos, generalmente a través de procesos de prueba-error y de la práctica. Su estudio resulta fundamental para la comprensión de la conducta humana ya que: aprendemos a caminar y a correr, a hablar y a escribir, a sumar y a restar,... aprendemos a preferir unas cosas a otras, $y$, por lo tanto, aprendemos también la diferencia entre lo bueno y lo malo, generando además prejuicios, gustos, preferencias, etc., lo que influye consciente e inconscientemente en nuestra toma de decisiones.

Puede, por ello, afirmarse que la cultura en general es la conducta aprendida, y que la cultura humana, en particular, es una cultura aprendida y acumulada - almacenada- a nivel individual en nuestra memoria y por medio de determinadas instituciones sociales evolutivas (instituciones sociales como: el leguaje humano natural, la moral, el derecho consuetudinario, el arte, los intercambios en el mercado, el dinero...). No obstante, no debemos adelantarnos ya que el tema de la formación de órdenes espontáneos y de instituciones sociales evolutivas lo trataremos más adelante.

De forma simplificada el esquema seguido en todo este proceso sería el siguiente:

a) Captación de estímulos exteriores — producidos por cambios de temperatura, por ondas trasmitidas por el aire, por variaciones de presión, por captación de moléculas en suspensión en el aire, etc.

b) Los referidos estímulos llegan a los receptores de nuestros órganos sensoriales - de nuestros sentidos-, produciendo una excitación nerviosa (sensación).

c) La excitación nerviosa es transmitida al cerebro, en concreto al córtex cerebral, que por su propia constitución y características, fruto de los procesos evolutivos que lo han generado, es capaz de apreciar subjetivamente determinadas cualidades que van siendo clasificadas siguiendo el complejo proceso que hemos descrito más arriba, proporcionando una cierta información —luego conocimiento. 
d) Gracias a nuestra estructura y constitución cerebral, así como a las clasificaciones y mapas mentales generados, somos capaces de memorizar, reproducir e imaginar.

e) Como resultado de dichas clasificaciones y capacidades de almacenamiento y reproducción, aprendemos, fundamentalmente, por medio de procesos de prueba-error e imitación, ajustando los criterios de clasificación, unificándolos y relacionándolos.

f) Todos estos procesos nos facilitan, no sólo que aprendamos, sino también que podamos trasmitir información a nuestros semejantes que, como tales, poseen estructuras mentales y capacidades similares a las nuestras (resultando clave en dicho proceso la aparición y evolución del lenguaje), lo que nos permite ir estableciendo redes de interrelaciones de intercambio de las que obtenemos importantísimos beneficios para el desarrollo de nuestra vida en sociedad.

g) Con el transcurso de dilatados periodos de tiempo, generamos pautas repetitivas de comportamiento que provocan la aparición de órdenes espontáneos que, a su vez, facilitan la aparición de instituciones sociales evolutivas capaces de almacenar ingentes cantidades de información, facilitando y sustentando con ello la vida en sociedad al darnos seguridad, estabilidad y la posibilidad de realizar ciertas predicciones, con todo lo que ello conlleva respecto de la facilitación de satisfacción de necesidades y de la supervivencia como especie, etc.

Tendríamos por tanto una etapa primera más biológica, sensorial e instintiva, otra más aprendida y cultural, y otra institucional, ámbitos todos ellos que se relacionan e interactúan de una forma muy compleja y que todavía no hemos sido capaces de descifrar en su totalidad. 
VI

LAS CLASIFICACIONES O CATEGORIZACIONES MÁS BÁSICAS Y PRIMITIVAS, Y SU RELACIÓN CON EL ORIGEN

DE LAS PRINCIPALES INSTITUCIONES SOCIALES EVOLUTIVAS (EL LENGUAJE, LA MORAL Y EL DERECHO)

Los primeros homínidos que habitaron la Tierra hace más de veinte millones de años, debieron tener una inteligencia y una capacidad cognitiva muy similar a la de los chimpancés o los bonobos actuales, sin embargo, como resultado de un complejo entramado de circunstancias que fueron marcando su evolución, aquellos homínidos primitivos comenzaron a evolucionar más rápidamente y a desarrollar determinadas capacidades específicas que provocaron la aparición de las primeras diferencias entre los grandes simios y lo que ya podrían considerarse los primeros antepasados del hombre (hace aproximadamente unos catorce millones de años). No obstante, los científicos no llegan a ponerse de acuerdo con las dataciones de épocas tan primitivas, ni tampoco con las distintas ramas evolutivas que llevaron finalmente a la aparición del género humano, quedando pendientes todavía muchas cuestiones fundamentales, como cuántas especies de homínidos se dieron, cuales llegaron a fabricar instrumentos y que otras habilidades poseían, etc. Sin embargo, sí parece confirmado que fue a partir de ancestros como el Australopitecus, y a través de los procesos evolutivos estudiados por la biología, la paleontología, la antropología, etc., que surgieron finalmente los primeros Homo Sapiens arcaicos, hace más de medio millón de años, los cuales evolucionaron hasta llegar al Homo Sapiens propiamente dicho, el cual poseía un aspecto y unas características típicamente humanas hace unos ciento veinte mil años.

Todo el proceso evolutivo mencionado es verdaderamente complejo, y en él se mezclan y fusionan aspectos, climáticos, físicos y biológicos, etc., y finalmente culturales. Es, por tanto, una materia tan complicada como interesante, pero que evidentemente supera con mucho los objetivos marcados en este trabajo, por lo que debemos centrarnos solamente en los aspectos que directamente lo afectan. No obstante, la teoría epistemológica moderna de la EAE 
que venimos describiendo, tiene también sustento en las aportaciones llevadas a cabo al evolucionismo en otras ciencias, y esto es importante destacarlo. Más en concreto, algunos antropólogos, biólogos, genetistas y otros científicos e investigadores están haciendo aportaciones recientes y muy interesantes, como es el caso en España de L. Castro y M. A. Toro ${ }^{13}$, que sostienen que el hecho de que los homínidos primitivos fueran capaces de desarrollar la capacidad de clasificar y de categorizar la propia conducta en función del valor atribuido a la misma, es decir, calificándola como positiva (buena) o como negativa (mala), les permitió también poder llegar a aprobar, o desaprobar, las conductas ajenas en esos mismos términos sencillos y dicotómicos, lo que supuso una gran ventaja adaptativa, más aún al irse perfeccionando y mejorando, fruto de la propia presión ejercida por la evolución, pudiendo así transmitir esos primitivos conceptos a su descendencia y al resto de componentes del grupo, con toda la valiosa información que ello conlleva a la hora de facilitar la supervivencia:

... la ventaja adaptativa que supuso la transmisión de información sobre el valor de la conducta, aprobándola o reprobándola, generó una presión de selección a favor del desarrollo de un sistema de comunicación más eficaz que permitió a los hijos comprender mejor la información que recibían. En otras palabras, generó una presión de selección a favor del desarrollo de la capacidad lingüística.

En ese mismo sentido:

la capacidad de categorizar utiliza las mismas estructuras cerebrales valorativas que controlan el aprendizaje individual y surgió cuando uno de nuestros antepasados homínidos fue capaz de procesar la información sobre el valor de la conducta aprendida, proporcionada por las estructuras cerebrales valorativas, mediante un simple par de proto-conceptos no verbales: positivo-negativo o bueno-malo. Esto representa la transformación de un mecanismo automático e inconsciente de categorización de la conducta utili-

${ }^{13}$ Castro, L y Toro, M. A. (2002). «La evolución del lenguaje». Diálogo Filosófico ${ }^{\circ}$ 53, pp. 275-290. 
zando para el aprendizaje individual un mecanismo de categorización conceptual.

Llegando a desarrollarse y a perfeccionarse con el transcurso del tiempo una nueva capacidad que consistía en poder categorizar la conducta aprendida mediante un código conceptual valorativo esencialmente dicotómico: positivo-negativo, bueno-malo ${ }^{14}$.

$\mathrm{Si}$ bien es cierto que las conductas de tipo instintivo y no aprendidas han sido algo suficiente para que muchas especies hayan sobrevivido y prosperen en la actualidad, sin embargo, otras especies se vieron favorecidas al desarrollarse en ellas la capacidad de aprender y de transmitir lo aprendido a las nuevas generaciones, aunque fuese en términos extremadamente sencillos. Llegados a este punto es importante destacar que lo que verdaderamente diferencia al ser humano de las demás especies que también cuenta con dicha capacidad de aprendizaje son peculiaridades como las siguientes: la primera de ellas se refiere al grado de complejidad y perfección alcanzado por el lenguaje humano como habilidad (fundamentalmente con el desarrollo de las funciones descriptiva y argumentativa), punto culminante de todo el proceso epistemológico que venimos describiendo en las líneas precedentes. Y, por otro lado, el haber sido capaces de desarrollar de forma no intenciona$\mathrm{da}$, al menos en sus orígenes, toda una serie de instituciones sociales evolutivas (dentro de las cuales se situaría el propio lenguaje humano natural concebido ahora como institución cultural), como: las normas morales, el derecho consuetudinario, el arte, las relaciones de intercambio que conocemos como mercado, etc.; cuya principal

${ }^{14} \mathrm{Y}$ decimos nueva capacidad ya que tal y como sostienen estos investigadores:

No parece existir un antecedente animal de transmisión de información sobre el valor de la conducta aprendida. El cuidado parental incluye en algunas especies conductas innatas que restringen los movimientos de la prole con el fin de evitarles determinados riesgos, pero no son prohibiciones acerca de conductas que los padres han aprendido a evitar y que han categorizado como malas. Es decir, según nuestra hipótesis, un chimpancé puede catalogar la conducta de otros individuos como favorable o desfavorable respecto a sí mismo y puede actuar en consecuencia, pero no es capaz de atribuir un proto-concepto de bueno o malo a su propia conducta y esto le impide categorizar la conducta de otro individuo como buena o mala para dicho individuo. 
característica es la de ser capaces de almacenar y transmitir una ingente cantidad de información. Estos procesos de generación, almacenaje y transmisión de información, permiten que se produzca un máximo aprovechamiento y división de la información (según fue calificado por F. A. Hayek) sin que la misma se pierda, dando lugar a procesos acumulativos, que son los que han llevado al hombre a diferenciarse del resto de las especies.

Por ello, muchos autores han sostenido que sólo el Homo sapiens ha sido capaz de conseguir un nivel tan alto de desarrollo de la transmisión cultural, al haber dado lugar a un proceso de evolución increíblemente rápido, eficaz, eficiente y de tipo acumulativo -entre dichos autores se encuentran el propio F. A. Hayek ${ }^{15}$ y M. Tomasello $^{16}$ - a través, fundamentalmente, de las referidas instituciones, de tal manera que la cultura humana se distingue por tratarse de un proceso acumulativo de generación y transmisión de información. Esto implica que dicho proceso basado, en su origen, en la clasificación que se hace de la conducta aprendida, sea, en realidad, un proceso de transmisión cultural revolucionario, que no se encuentra en primates no humanos. De esta manera, los primitivos homínidos reunieron varias capacidades fundamentales: la capacidad de imitar el comportamiento de sus semejantes, la capacidad de aprobar y desaprobar las acciones de los otros categorizándolas, y la capacidad de generar y transmitir una forma de acumulación de la herencia cultural (información acumulada) de una manera muy eficaz y eficiente. Paralelamente esa capacidad de abstracción y de categorización de las cosas y las conductas, etc., tuvo su reflejo en la aparición del leguaje primitivo, así como en los primeros criterios morales sobre lo que estaba «bien» y lo que estaba «mal», que acciones debían realizarse y cuales no, lo que con posterioridad daría lugar a las primeras normas abstractas, morales y de obligado cumplimiento originadoras de un primitivo derecho.

La aparición espontánea del lenguaje humano se debió, por tanto, a múltiples factores que facilitaron el desarrollo de la capacidad

${ }^{15}$ A lo largo de toda su obra, pero fundamentalmente en La Fatal Arrogancia, y en Derecho, Legislación y Libertad.

${ }^{16}$ Tomasello, M. (1999). The Cultural Origins of Human Cognition. Harvard University Press. 
lingüística y, simultáneamente y de forma interconectada, la aparición de otras instituciones también evolutivas. Es decir, partiendo de una base biológica y genética, surgida en un determinado entorno y circunstancia, se generan una serie de capacidades cada vez más perfeccionadas: A) de abstracción, B) de generalización, C) de descubrimiento, D) de transmisión, E) de acumulación de información, y D) de institucionalización por medio de órdenes espontáneos. Generándose así una sucesiva e imparable evolución cada vez más compleja y acelerada. Todo ello va a fomentar la unión dentro del grupo, y del grupo con otros grupos con los que se produce compatibilidad; provocándose, a la inversa, separación o alejamiento de otros grupos. Todos estos procesos permiten transmitir información sobre conductas y experiencias antes de tener que experimentarlas, y de una forma genérica. Gracias a este proceso y a la analogía de situaciones, se van favoreciendo las que se califican como positivas y buenas, y se limitan o eliminan las que se califican como negativas, malas y perjudiciales. Aumentando la transmisión cultural acumulativa con disminución de errores, y un incremento de la seguridad y la corrección respecto de las acciones que se consideran adecuadas.

En todo este proceso tuvo, por tanto, un papel fundamental la capacidad lingüística, ya que supuso una ventaja adaptativa básica que proporcionó la posibilidad de transmitir información sobre la conducta aprendida, aprobándola o reprobándola, ejerciendo una gran presión selectiva a favor del desarrollo de un sistema de comunicación cada vez más eficaz, favoreciendo el desarrollo intelectual y la capacidad de descubrimiento e innovación. Surgió así un proceso de feedback o retroalimentación, que posibilitó tanto el desarrollo intelectual, como el desarrollo de un sistema de comunicación capaz de transmitir información que, a su vez, es fundamental para la más correcta toma de decisiones por parte de los individuos. La ventaja adaptativa de adquirir este tipo de conocimientos y el poder acumularlos es enorme y está fuera de toda duda, resultando evidente que sin la utilización de un lenguaje verbal hubiese sido prácticamente imposible todo este proceso.

Siguiendo con nuestro análisis, nos encontramos con que resulta muy complicado saber cuando empieza la evolución hacia un sistema arbitrario de signos lingüísticos organizados, que fue lo 
que permitió una mayor flexibilidad a la hora de transmitir información. No obstante, parece evidente que dicho origen puede encontrarse en la transmisión básica de información muy simple, como la que venimos indicando y que muy probablemente fue la iniciadora del proceso, con las mencionadas clasificaciones del tipo «Si/No», «Bueno/Malo»... que se fue complicando en el proceso evolutivo hasta alcanzar formas cada vez más y más elaboradas que desembocarían en la transmisión de información del tipo: «Tu no hagas eso, es malo, o tendrás un castigo», etc. Para que este proceso se dé es imprescindible el desarrollo de manera simultánea de la capacidad intelectual sobre la base de una estructura cerebral con capacidad clasificatoria que permita percibir la conducta en función de esa dicotomía básica (positiva frente negativa; bueno frente a malo) que, en su origen, fueron categorías o conceptos no verbales que surgen cuando comienza el referido proceso de categorización valorativa asimétrica de las acciones, pero que rápidamente debió tener un reflejo en conceptos verbales simples.

Es también muy importante la trascendencia que para el ser humano en general tiene la aprobación y la desaprobación de la conducta por parte del resto del grupo, como actividad orientadora del comportamiento desde la infancia (la importancia de esta capacidad se deriva de que podía llevar a la integración o a la expulsión del grupo, lo que podía implicar bien la muerte o bien la supervivencia del individuo). Tal y como citan Castro y Toro:

George C. Williams en la introducción de su ya clásico libro Adaptation and Natural Selection (1966) sugiere que las cualidades mentales avanzadas pueden originarse como un efecto accidental de la selección para la capacidad de comprender y recordar instrucciones verbales simples en los primeros años de la vida. Williams argumenta que incluso hoy en día la muerte accidental es una importante causa de mortalidad infantil y que muchas de estas muertes accidentales se podrían haber evitado si las victimas hubiesen comprendido y recordado las instrucciones verbales y hubiese sido capaces de sustituir efectivamente los símbolos verbales por la experiencia real. Esto pudo haber sido así también en condiciones de vida más primitivas. Nosotros coincidimos con este planteamiento de Williams que conlleva, como él mismo sugiere, una presión selectiva para adquirir competencias verbal tan 
pronto como sea posible. Pinker (1994) también recoge y defiende este argumento cuando sugiere que tal vez no sea una mera coincidencia que la explosión del vocabulario y los inicios de la gramática estén ligados al desarrollo locomotor del niño, ya que la capacidad de locomoción aparece en torno a los quince meses de vida. ${ }^{17}$

No cabe duda de que la evolución es algo extremadamente complejo, y en ella se interrelacionan múltiples factores (algunos todavía desconocidos para los investigadores). La propia capacidad lingüística y las normas de convivencia (moral y derecho), evolucionaron al mismo tiempo que lo venía haciendo la selección natural, influyéndose mutuamente unas en otras. Los homínidos fueron desarrollando la capacidad conceptual de categorizar la conducta propia en términos de valor, desde las formas más sencillas hasta las más elaboradas que hoy conocemos. Así se podía aprobar o desaprobar las conductas, aprender de ellas y transmitirlas con posterioridad a las siguientes generaciones. La capacidad de transmisión de la experiencia sobre lo correcto o lo incorrecto, lo que se debe y lo que no se debe hacer, supuso una ventaja adaptativa basada en la formación, transición y acumulación de información que influyó en los propios procesos de selección, pasando a ser fundamental la formación de sistemas de comunicación eficaces y de su almacenamiento a través del lenguaje y la cultura. Todo este proceso facilita la consecución de fines de una forma más sencilla y segura, generan paz y prosperidad, mejorando la capacidad de adaptación y la evitación de decisiones erróneas.

El proceso evolutivo que llevó al hombre a diferenciarse del resto de los animales, generando instituciones sociales evolutivas, y más en concreto el propio leguaje humano, tiene, de esta manera una base evolutiva biológica que, a partir de determinado estadio de la evolución, comienza a entrelazarse con la evolución -también filogenética- pero de naturaleza cultural, influyéndose mutuamente y marcando sucesivos y diferentes nichos evolutivos para la especie. Dentro de esta evolución biológico-cultural filogenética que marca la base o sustrato del que parte el ser humano actual (en la que deben tenerse en cuenta sus diferencias y matices) se produce

${ }_{17}$ Op. Cit. 
la propia evolución ontogénica del individuo, partiendo de una complejísima urdimbre en la que se almacena una infinita cantidad de información. Se trata del conjunto de toda nuestra herencia, materia prima de la que parte cada individuo desde su nacimiento para desarrollar su particular evolución ontogénica que, a su vez tiene una parte de desarrollo biológico y una parte de desarrollo cultural - ambos inseparablemente fusionados-, que se mezclan e influyen mutuamente de una forma tan compleja que nos resulta prácticamente imposible comprenderlos en su totalidad. Además, debe tenerse en cuenta que todo ese proceso evolutivo filogenético (biológico-cultural) tiene una duración de millones de años y lleva en su interior toda la amalgama de cientos de millones de desarrollos ontogénicos (biológicos-culturales) de cada uno de los diferentes individuos que fueron formando parte del mismo, influyéndose entre si cada uno de los infinitos factores mencionados, de manera que resulta imposible conocerlos en su totalidad y poder ponderarlos adecuadamente. ¿Cabe mayor complejidad?

\section{VII}

\section{LO CONCRETO Y LO ABSTRACTO}

$\mathrm{Al}$ igual que comentamos al hablar del inconsciente y de la consciencia, cuando nos referimos a las ideas de concreto y abstracto, nos encontramos también con la falsa apariencia de que estamos ante dos aspectos totalmente distintos: lo que serían «experiencias inmediatas» por un lado, y lo que serían «conceptos», por otro. Sin embargo, esa primera impresión no es cierta y puede llevar a engaño. Este equívoco se deriva de una errónea apreciación que nos hace creer que las cualidades sensoriales observadas en los objetos son atributos de los propios objetos, y que, por tanto, los acontecimientos mentales se forman por elementos sensoriales fijos y estables.

Tal y como ya hemos indicado, para Hayek la percepción sensorial es un acto de clasificación, y lo que percibimos nunca son propiedades objetivas y exclusivas de los objetos individuales, sino propiedades que identificamos subjetivamente como comunes en los objetos analizados. Lo percibido del exterior son sólo propieda- 
des que identificamos en los miembros de una clase creada subjetivamente y que han formado uniones (o eslabonamientos mentales) en el pasado. Esto nos lleva a una conclusión fundamental:

Las cualidades que atribuimos a los objetos experimentados no son, estrictamente hablando, propiedades de esos objetos en absoluto, sino un conjunto de relaciones por las que nuestro sistema nervioso las clasifica o, por decirlo de diferente manera, todo lo que sabemos sobre el mundo está formado por teorías, y toda la «experiencia» que podemos hacer consiste en cambiar estas teorías.

Esto quiere decir, también, que lo que percibimos del mundo externo nunca son ni todas las propiedades que se puede decir que poseen los objetos particulares, ni siquiera sólo algunas de las propiedades que estos objetos, de hecho, poseen físicamente, sino siempre sólo ciertos «aspectos», ciertas relaciones con otras clases de objetos que asignamos a todos los elementos de las clases en las que situamos los objetos percibidos. Esto, a menudo, puede comprenhender relaciones que, objetivamente, no pertenecen todas al objeto particular, pero que simplemente las adscribimos a él como el miembro de la clase en que lo situamos como resultado de alguna colocación accidental de las circunstancias que se produjeron en el pasado. ${ }^{18}$

Si aceptamos que finalmente puede existir un mundo físico distinto del mundo de los «fenómenos» que podemos llegar a percibir en base a nuestras limitaciones, esto supondría que el primero puede tener, por tanto, características y propiedades que podríamos no estar percibiendo correctamente, y otras que no podríamos ni tan siquiera llegar a conocer jamás. Todo esto implicaría que no existiría la dicotomía establecida entre «concreto» y «abstracto», ya que incluso las cualidades sensoriales consideradas como más elementales resultan ser siempre «abstracciones», pues las establecemos por medio de conjuntos de relaciones que hemos ido aprendiendo a asociar a determinados estímulos que, en un sentido estrictamente «físico", podrían tener, o no tener, idénticas propiedades, o, incluso, ser totalmente diferentes a los fenómenos percibidos.

${ }^{18}$ Hayek, F. A., El orden sensorial. Op. cit., p.244-245. 
El principal problema que se desprende de los hechos analizados es que no somos capaces de darnos cuenta de que nuestras sensaciones y percepciones son ya parciales e incompletas desde el origen (y lo mismo sucede con cada una de las etapas generadoras de nuestro conocimiento del universo que nos rodea), precisamente porque nuestro sistema cognitivo ha evolucionado para que sea así, y este hecho ha marcado nuestra evolución como especie. Sin embargo, el inconveniente generado por nuestras incompletas percepciones se ve suplido por nuestra capacidad para completar aquello que nos falta para poder centrarnos en determinados aspectos particulares (seleccionados tanto consciente como inconscientemente). No obstante, aunque no tiene mucho sentido tratar de diferenciar entre la representación «concreta» recibida por la percepción sensible y las «abstracciones» derivadas de procesos mentales superiores, si tiene sentido distinguir entre datos inmediatos de la consciencia y los procesos posteriores de reordenación y clasificación de dichos datos conscientes que darían lugar al pensamiento conceptual.

\section{VIII \\ EL PENSAMIENTO, LOS CONCEPTOS Y EL LENGUAJE}

Según lo que hemos visto en líneas precedentes (y al margen de la elección inconsciente), seleccionamos la información a través de dos mecanismos: la atención (suprimiendo o bloqueando determinada información y concentrándonos en otra), y la abstracción (que consiste en dar relevancia a ciertas propiedades de un estímulo, sin que se tomen en consideración otras propiedades del mismo). En los animales superiores la capacidad de abstracción se desarrolla, sobre todo, a partir de los procesos de aprendizaje de discriminación y, en el caso del hombre, además, por la formación de conceptos, que es un proceso de abstracción intelectual mediante la selección. Es decir, un proceso activo en el que se seleccionan los elementos que se identifican como comunes en los objetos sobre los que se aplica, integrándolos en clases, y agrupando los nuevos conocimientos y experiencias con los conocimientos y experiencias ya almacenados en la memoria. 
El motivo de toda la referida selección de información, incluida también la efectuada a la hora de formar conceptos, se debe a que la clave del pensamiento no es que el organismo reciba la máxima información posible del exterior y de su propio interior, sino que reciba la información suficiente y adecuada en cada caso, así como que, de entre el gran número de respuestas que pueden darse frente a cada estímulo, el organismo pueda responder de la manera más conveniente a cada uno de ellos, facilitando la toma de decisiones al actuar. En el caso del ser humano, adquieren especial relevancia los mecanismos aprendidos a través de procesos mentales y del pensamiento; y no sólo los patrones específicos de respuesta (instintos) o los procesos de ensayo y error. El pensamiento es básicamente la adquisición de conocimiento o información que se retiene en la memoria y tiene forma de procesos simbólicos, es decir, de procesos de representación de lo real mediante símbolos (que para el ser humano evolucionado suelen ser las palabras). Se trata, por tanto, de un proceso complejo y esencialmente interno, que implica representaciones simbólicas de hechos y objetos no presentes en la realidad inmediata, gracias a los cuales, al enfrentarnos a un problema (situación que detiene la acción y los esfuerzos del organismo para alcanzar un objetivo), hacen posible reconocerlo como tal, optar entre alternativas y resolverlo. El producto del pensamiento suele ser un patrón de símbolos que atribuye cierta propiedad, o propiedades a algo, y eso, tal y como hemos ya señalado, es lo que llamamos conceptos, indicando un número limitado de características destacables e ignorando las demás. Se trata de una actividad y una creación de la mente tan compleja y amplia que resulta muy difícil de definir, y en la que quedan incluidas tanto la actividad racional, como las abstracciones de la imaginación y aspectos no conscientes.

Por su parte el lenguaje humano ${ }^{19}$ es la expresión del pensamiento mediante signos en forma oral y escrita, y como tal instrumento

19 Por motivos de extensión no podemos tratar en el presente trabajo los procesos de evolución que llevaron al hombre a poder adquirir su capacidad para desarrollar el leguaje tal y como lo conocemos hoy en día. Son procesos también muy difíciles de analizar, donde se mezcla la previa evolución biológica con la posterior evolución cultural. En este último campo, y en la parte que se refiere al estudio de la evolución cultural de las distintas lenguas, resulta muy interesante las aportaciones realizadas por la lingüística 
de comunicación del pensamiento y de comprensión de la realidad tiene una serie de características que son las siguientes:

a) Es un sistema de señales de segundo nivel, formado por palabras y signos lingüísticos.

b) La palabra es un símbolo, además de poder ser una señal compleja. Entendiendo tanto el símbolo, como la señal, como signos, es decir, cosas o sucesos físicos que representan, o están en lugar de otras cosas o sucesos distintos de ellos. Mientras que la señal es una experiencia basada en la sucesión regular de dos acontecimientos, asociándolos por ello en nuestra mente; el símbolo se basa en una convención social, en la existencia de una regla social que atribuye a tal símbolo, tal significado. Por ello, los llamados leguajes animales son más bien conjuntos de señales, sólo excepcionalmente se han observado en grupos de animales gregarios muy evolucionados, la utilización de algunos símbolos aislados que requieran ser socialmente aprendidos (caso de algunos primates y sus rudimentarios sistemas de símbolos de aviso frente a posibles depredadores).

En este sentido, el hombre es el único animal que habla, entendiendo por habla, o leguaje hablado, el empleo de sistemas complejos de símbolos capaces de permitir que se den dos características típicamente humanas: la comunicación de significados, sentimientos, pensamientos e ideas abstractas entre individuos (datos que la mente humana transforma en información), así como, la más característica de todas, consistente en permitir el establecimiento de

histórica (también denominada en ocasiones lingüística diacrónica o comparada), que es la disciplina lingüística que se ocupa fundamentalmente del estudio de los cambios experimentados por las lenguas con el transcurso del tiempo, y el proceso evolutivo que estas experimentan por la influencia de diversos factores, por lo que el núcleo de su análisis es la evolución diacrónica de las lenguas y su relación genética. Precisamente, debido a la gran complejidad que entrañan estas materias, resulta imprescindible que sus resultados se contrarresten con las aportaciones de cada una de las diferentes disciplinas que las estudian, como la historia, la arqueología, la antropología, la biología y la genética, etc. Ya que los estudios multidisciplinares resultan de gran importancia para poder hacer una reconstrucción cronológica de los complejos procesos de evolución que afectan a las lenguas, de igual manera que sucede con la mayoría de los estudios de procesos evolutivos en general. 
relaciones y órdenes espontáneos extremadamente complejos, que permiten, con el tiempo, la generación de instituciones sociales evolutivas (moral, religión, derecho, mercado, dinero...) que resultan imprescindibles para la aparición y evolución de lo que Hayek denominó la «Gran Sociedad» humana.

Las conexiones entre los impulsos sensoriales y el aparato de expresión altamente desarrollado que posee el hombre, sin duda que amplían enormemente los medios de clasificación de que disponen, y son, probablemente, de la mayor importancia en la posibilitación del pensamiento abstracto. También son especialmente importantes porque, en el aprendizaje del sistema de símbolos desarrollado por su especie, el individuo puede utilizar, al ordenar su experiencia presente, no sólo su propia experiencia, sino, en alguna medida, también la experiencia de su especie. ${ }^{20}$

Las diversas instituciones integradas en el orden extenso - entre ellas el mercado- nos permiten recoger esa diseminada información y establecer la existencia de modelos supraindividuales. Una vez desarrolladas las instituciones y tradiciones basadas en tales modelos, huelga el acuerdo (imprescindible a nivel tribal) sobre fines comunes, resultando posible, por el contrario, la utilización de la información ampliamente diseminada, así como el mejor aprovechamiento de la habilidades de cada cual para alcanzar una pluralidad de fines. ${ }^{21}$

En lenguaje nos sirve para decir y expresar algo, y, en este sentido, las palabras serían expresiones de conceptos, de tal manera que el lenguaje formaría un sistema que posibilitaría la interpretación y la representación de lo que entendemos por realidad.

Tal y como hemos visto, clasificando es la manera en que el hombre da sentido a los estímulos que le rodean, estableciendo relaciones y codificando los aspectos entendidos subjetivamente como comunes de los objetos y de los acontecimientos. Así se van formando conceptos, es decir, símbolos que representan clases de objetos o de acontecimientos, en los que se observan subjetivamente propiedades comunes, organizándose, según hemos visto, el

\footnotetext{
${ }^{20}$ Hayek, F. A. El orden sensorial. Op. cit., p.233.

${ }^{21}$ Hayek, F. A. (1990). La Fatal Arrogancia (los errores del socialismo), p.46.
} 
conjunto de sensaciones que se perciben del exterior. Es precisamente la capacidad de abstracción la que nos permite seleccionar determinadas propiedades de los estímulos del ambiente prescindiendo de otras, mientras que para concretar y fijar los aspectos comunes de objetos y acontecimientos nos valemos del lenguaje, ya que las palabras representan los conceptos más o menos generales, más o menos abstractos. A su vez, los conceptos pueden describirse identificando los rasgos más característicos que somos capaces de captar de los objetos - $\mathrm{o}$ hechos- y especificando las relaciones apropiadas entre estos rasgos. Adquirir un concepto es adquirir la comprensión de una regularidad detectada que antes no se conocía. Desde muy pequeños los niños van adquiriendo conceptos y esto les va ayudando a transformar su confuso mundo infantil, organizando y sistematizando la información que van recibiendo. Los conceptos se van asimilando al mismo tiempo que se va aprendiendo el lenguaje, por lo que se van asociando las diferentes percepciones al correspondiente símbolo verbal. Una vez adquirido un concepto se puede usar para transmitir información, resolver problemas nuevos o utilizarse como base de un aprendizaje aún más complejo.

Llegados aquí habría que analizar cuales son las relaciones entre pensamiento y lenguaje. Si bien parece claro que el lenguaje - las palabras - son un medio fundamental para la expresión y transmisión del pensamiento, parece también evidente que no son la misma cosa, ya que existen ciertas distinciones entre lo que es el pensamiento (ideas, conceptos), y el lenguaje (las palabras o expresiones verbales de ese pensamiento). A este respecto hay distintas posturas: unas consideran que hay una separación completa entre pensamiento y su expresión lingüística, considerándolos independientes, entendiendo que el pensamiento es lo que es independientemente de las palabras con que se exprese, si es que las hay. Frente a esta postura, que es la adoptada por el evolucionismo austriaco, existen otras que, muy al contrario, consideran que existe una identidad entre ambos, y que pensamiento y expresión lingüística son algo inseparable.

Lo cierto es que la relación entre ambas es muy compleja y estrecha, y nos lleva a través de todo el proceso analizado hasta su culminación: 
a) Los estímulos

b) Los sentidos

c) Los procesos de clasificación y reclasificación: la mente genera continuos procesos de clasificación a través de conexiones adquiridas que reproducen relaciones sentidas entre los estímulos físicos (siempre de forma parcial e imperfecta), así como de reclasificación de los propios elementos de las clases de los mecanismos sensoriales preconscientes.

d) Los modelos del mundo físico: que en realidad son reproducciones más o menos distorsionadas de las relaciones entre el mundo físico y la clasificación de nuestros sentidos.

f) Las abstracciones: determinadas por medio de conjuntos de relaciones que hemos aprendido a unir a determinados estímulos que en sentido estricto y puramente físico podrían, o no, tener propiedades idénticas o ser, en realidad, totalmente diferentes, según ya hemos indicado.

g) La calificación: designamos o damos nombre a las abstracciones, tras atribuirles cualidades y propiedad.

h) El pensamiento conceptual.

i) El lenguaje (oral y posteriormente escrito).

IX

\section{LA RAZÓN}

Analizando los procesos de formación de modelos mentales y de conceptos, comprendemos lo absurdo que resulta querer identificarlos con ideas como la de conocimiento absoluto, universal o eterno. Debemos ser conscientes de que la propia mente humana es fruto de la evolución y se debería concebir ella misma como un modelo (microcosmos) de ese macrocosmos en el que existe, tal y como nos recuerda Hayek, que viene a insistir en el hecho de que dentro del macrocosmos formamos microcosmos que tratan de reproducir ciertos aspectos de aquel que tratan de facilitar nuestra supervivencia, y que tendrán más probabilidades de tener éxito si son adecuados al tiempo y lugar en el que se desarrollan. Esta idea de que los modelos, los conceptos y las teorías vendrían a ser microcosmos, es fundamental para la epistemología austriaca, así 
como para sus planteamientos metodológicos, como seguidamente veremos.

Siendo los modelos estructuras internas que reproducen parcialmente las relaciones entre acontecimientos externos, Hayek afirma lo siguiente.

La oportunidad de la persistencia de cualquier estructura dada, evidentemente, aumentará si no sólo acierta a responder apropiadamente a las influencias dañinas o benéficas y a algunos síntomas de tales factores, sino si posee, también, la capacidad de retener una «memoria» de las conexiones entre los acontecimientos que, frecuentemente, preceden a tales influencias y a estas mismas influencias, $\mathrm{y}$, consiguientemente, si se vuelve capaz de aprender a desempeñar la respuesta apropiada allí donde aparecen aquellas señales. Las estructuras relativamente complejas, que sin esta capacidad no existirían mucho tiempo, pueden adquirir un grado considerable de estabilidad a través de ella. ${ }^{22}$

Quizá el aspecto más fundamental de las enseñanzas de la Escuela Austriaca respecto de la razón humana (entendida ésta como la capacidad de discurrir, reflexionar y aplicar la inteligencia), sea la afirmación de que la misma no ha sido la guía de la evolución cultural del hombre, sino que, en realidad, la razón es en parte producto de dicha evolución (como lo es de la propia evolución biológica), a través de la adquisición de determinadas habilidades desarrolladas mediante procesos de prueba y error, así como de conductas que son transmitidas por medio de actos de imitación, y gracias a la capacidad de aprendizaje, etc. La razón es, por tanto, una cualidad limitada e imperfecta (tal y como siempre sostuvo Mises en sus obras), y se ha ido desarrollando de forma paralela a la evolución cultural. Por todo ello Hayek viene a decir lo siguiente:

La ciencia evidencia que no fue esa realidad psíquica que denominamos mente lo que originó la aparición del orden civilizado, y menos aún que, llegada a cierto grado de desarrollo, asumiera el control de su evolución futura. Lo que realmente sucedió fue que

${ }^{22}$ Hayek, F. A., El orden sensorial. Op. cit., p. 225. 
tanto la mente como la civilización alcanzaron simultáneamente su potencial actual. Eso que llamamos mente no es algo con lo que el individuo nace - como nace con un cerebro- ni algo que el cerebro produce, sino una dotación genética (p.e., un cerebro con una estructura y un volumen determinados que nos permite aprender de nuestra familia, y más tarde en el entorno de los adultos, los resultados de una tradición que no se transmite por vía genética. ${ }^{23}$

De esta manera el proceso evolutivo de la sociedad no es un proceso ni asimilable en su totalidad ni controlado por la razón, por ello, los austriacos hacen gran hincapié en que cuando se apliquen análisis críticos al estudio de las normas reguladoras de la vida en sociedad y de sus instituciones evolutivas, el beneficio de la duda deberá favorecer siempre a la norma evolutiva existente. Recalcando, igualmente, que esto no implica que deba entenderse que toda norma evolutiva deba ser considerada siempre como adecuada y positiva, pues no siempre es así, sino que para analizarla críticamente deberá hacerse de la misma un previo y profundo estudio histórico, y un posterior análisis basado en las ciencias jurídica y económica.

Por todo lo expuesto respecto de la razón, cabe afirmar que alguien que naciese con una dotación genética insuficiente o alguien que no hubiese estado nunca en contacto con la civilización, no podía tener acceso a la racionalidad típicamente humana ${ }^{24}$. Por ello, parece lógico poder afirmar que se ha producido en el hombre una evolución inicialmente biológica (que dio lugar a la aparición de los instintos típicamente animales), dotación genética a la que se sumó la formación de determinados hábitos, conductas y costumbres - que se fueron desarrollando en múltiples entornos. A dichos factores se añadió un tercero, fruto de ambos: la aparición de la propia capacidad racional del hombre. Esta evolución conjunta continúa hoy día con todos sus factores interrelacionándose entre sí y con el entorno: el hombre continúa evolucionando

${ }^{23}$ Hayek, F. A., La fatal arrogancia. Op. cit., págs. 56 y ss.

${ }^{24}$ Motivo por el cual el evolucionismo austriaco siempre ha criticado el análisis de tipo «robinsoniano» aplicado al estudio de las instituciones sociales evolutivas, aunque pueda resultar muy útil en otros niveles da análisis, como es el caso del estudio de la acción humana, las relaciones de intercambio y la función empresarial. 
biológicamente — con la lentitud característica de este proceso-, sigue disfrutando de instintos, aunque muy restringidos y limitados en comparación con los de los animales; además, está inmerso en un mundo cultural, un orden evolutivo espontáneo formado por costumbres, tradiciones, normas, instituciones, etc., que le han permitido controlar y superar, en cierta medida, sus instintos, poseyendo, además, las fabulosas capacidades que le otorgan el leguaje y la razón. Y es precisamente por la forma tan extremadamente compleja que tienen estos factores de entrelazarse e interactuar, por lo que resulta tan difícil el análisis y estudio del orden social.

Siendo esto así, el científico que aborde el estudio de esta materia tiene que ser especialmente cauto. Siendo éste el motivo de que los autores austriacos rechacen la epistemología del racionalismo extremo, que se cree capaz de alcanzar el conocimiento de verdades absolutas, universales y eternas gracias a la mente humana y a la capacidad racional.

\section{$X$ LA VERDAD Y LA CERTEZA}

Según todo lo que venimos analizando en el presente trabajo y si admitimos que la inteligencia humana es limitada y que la razón puede cometer errores, no tenemos más remedio que afirmar que todo conocimiento humano es falible y, por tanto, incierto. Karl Popper (que diferenció entre verdad y certeza en el sentido de considerar a la verdad como un conocimiento incompleto y mejorable, y a la certeza como un conocimiento absoluto e inmutable), nos recuerda a este respecto lo siguiente:

Como nunca podemos conocer nada con seguridad, simplemente no vale la pena buscar la certeza; pero sí vale la pena buscar la verdad; y esto lo hacemos principalmente buscando equivocaciones, a fin de poder corregirlas. ${ }^{25}$

${ }^{25}$ Popper, K. L., (1994): En busca de un mundo mejor. Barcelona. Ediciones Paidós, p.19. 
Y en esa misma línea de pensamiento, Mises no dudaba en afirmar lo siguiente:

El escepticismo de Hume fue una reacción contra el postulado de la certeza absoluta, la cual, para el hombre, es inalcanzable. Los santos que se dieron cuenta de que sólo la revelación podría dar al hombre certeza absoluta estaban en lo cierto. La humana investigación científica no puede ir más allá de los límites establecidos por la insuficiencia de los sentidos y la estrechez de la mente del hombre. No hay demostración deductiva posible del principio de causalidad ni de la inferencia enriquecedora de la inducción perfecta. Sólo se puede recurrir a la no menos indemostrable afirmación de que haya una estricta regularidad en la asociación de todos los fenómenos naturales ${ }^{26}$.

Esto quiere decir que el científico debe renunciar a perseguir el conocimiento de certezas (conocimiento seguro o verdades absolutas sin posibilidad de error) y debe limitarse a buscar simples aproximaciones a la verdad, entendida como la conformidad de las cosas con el concepto o modelo que de ellas elabora la mente. Por ello, el científico debería buscar exclusivamente «verdades» (que, según esta concepción, pueden entenderse como parciales, incompletas, etc.), y no «la certeza» (que por definición no pude ser limitada o «incierta»). En este sentido, sólo podría permitirse la licencia de hablar de forma impropia de certeza dentro de modelos restringidos y parciales (microcosmos), perdiéndose tal conocimiento al ir integrándose en modelos superiores, y careciendo de todo sentido al referirlo al cosmos. Esto resulta todavía más evidente si nos referimos a las ciencias sociales, donde el científico se enfrenta con una ingente masa de información incompleta que se está continuamente generando, donde existen múltiples procesos intermedios y donde el conocimiento más importante es tácito, se encuentra disperso y no es articulable por quien lo posee. Se trata de un ámbito de estudio donde a las limitaciones humanas se une la infinita complejidad del objeto estudiado.

${ }^{26}$ Mises, L., (2003): Teoría e Historia. Madrid. Unión Editorial, p. 63. 
Salvo que de forma impropia, según hemos dicho, nos estemos refiriendo a convencionalismos o sistemas muy sencillos, no puede existir un criterio de certeza, por lo que, aunque lo hubiésemos alcanzado por azar, nunca podríamos tener seguridad de ello. Incluso los sistemas lógico-matemáticos de conocimiento son incompletos según se demostró con los Teoremas de la incompletitud del matemático y filósofo Kurt Gödel. No obstante, y sin que ello venga a contradecir lo que venimos sosteniendo en este trabajo, se aprecia un criterio racional de progreso en esa búsqueda infinita de la verdad (infinita en el sentido de que nunca se alcanza, ya que de cada solución a un problema surgen toda una multiplicidad de nuevos dilemas). Por ello, debemos ser conscientes de que a pesar de ser capaces de conocer cada vez más cosas y de ir lentamente acercándonos a eso que hemos denominado verdad, no podemos librarnos de todos los errores enumerados en líneas precedentes y de las deficiencias e imperfecciones de nuestras mentes y de la razón, a las cuales estamos condenados como seres humanos limitados y falibles, por ello en el proceso de investigación científica, el estudioso no puede evitar estar sometido a toda una serie de limitaciones muchas de las cuales ni siquiera sabemos cuales son, y sabiendo además que es el propio científico el que ya de entrada decide sobre extremos como:

a) Que objetos cree que vale la pena iniciar la investigación (despreciando otros sin conocer plenamente las repercusiones de esta elección en la propia investigación).

b) Introduce en sus razonamientos juicios y valoraciones personales (determina si las evidencias son suficientes, si los argumentos escogidos son lo bastante rigurosos, si incluye argumentos de autoridad, etc.).

c) También selecciona el propio método de la investigación y como desarrollarlo, etc.

Ante este panorama de imperfecciones, errores y adulteraciones, difícilmente se puede afirmar que el conocimiento científico pueda llegar a alcanzar certeza absoluta alguna. Y es por ese motivo por lo que tanto Hayek como Mises se incluyen expresamente en esta corriente de pensamiento que exige al científico un profun- 
do ejercicio de modestia intelectual. Es más, Mises en sus obras de madurez mantiene con firmeza lo siguiente:

El conocimiento humano está condicionado por la capacidad de la mente humana y por la extensión del ámbito en que los objetos producen sensaciones. Tal vez haya en el universo cosas que nuestros sentidos no pueden percibir y relaciones que nuestra mente no puede comprender. También puede ser que haya fuera de lo que llamamos el Universo otros sistemas de cosas acerca de los cuales nada podemos averiguar, porque, por ahora, ningún indicio de su existencia llega a nuestro ámbito de forma que pueda modificar nuestras sensaciones. También podría ser que la regularidad en la asociación de fenómenos naturales que nosotros observamos no sea eterna, sino pasajera y que prevalezca solamente en el presente estadio de la historia del universo (que puede durar millones de años), pero que podría algún día ser reemplazada por otra estructura.

Pensamientos como éstos y otros similares pueden inducir a un científico cuidadoso a tener mucha cautela en la formulación de los resultados de sus estudios. Al filósofo le compete ser aún más cauteloso al manejar las categorías a priori de la causalidad y la regularidad en la secuencia de los fenómenos naturales. ${ }^{27}$

De esta manera, la única forma de acercarse correcta y paulatinamente a la verdad es, ante todo, ser conscientes de los límites de la razón, dando prioridad como método de avance en nuestro conocimiento a la crítica y a la competencia entre teorías, conjeturas y modelos. Sólo si el científico reconoce sus limitaciones y da la relevancia adecuada a los procesos de crítica, es posible que avance la ciencia y nuestro conocimiento. Tal y como indica Popper, la raíz de nuestra ignorancia se encuentra en que nuestro conocimiento sólo puede ser finito, mientras que nuestra ignorancia es necesaria e inevitablemente infinita:

... nos conduce a la importante idea de que puede haber grandes diferencias entre nosotros con respecto a los detalles menores de lo que quizá podamos conocer, pero que todos somos iguales en nuestra infinita ignorancia. ${ }^{28}$

${ }^{27}$ Mises, L., Teoría e Historia. Op. cit., p. 63.

${ }^{28}$ Popper, K. L., En busca de un mundo mejor. Op. cit., p. 64-65. 
Sin embargo, parece que a lo largo de la historia el hombre siempre ha estado guiado por la necesidad de buscar a toda costa certezas a su alrededor. A pesar de disponer de una información parcial, tenemos la tendencia a crear modelos que, a pesar de ser subjetivos e incompletos, los identificamos con certezas absolutas. Algunos autores como Allan Walstad, consideran que se trata de procesos neurológicos inconscientes y adquiridos por evolución y herencia genética, que tienen como finalidad facilitar el desarrollo de nuestras acciones, disminuyendo la angustia de tener que decidir sobre la base de un conocimiento incompleto, lo que facilita nuestra capacidad decisoria y nos da una sensación de seguridad en un entorno incierto y cambiante.

Respecto del conocimiento absoluto Popper ya advertía de los peligros del esencialismo de tipo aristotélico, abogando por una postura nominalista ${ }^{29}$, mientras que otros autores como Ronald Giere tras llegar a la misma conclusión respecto de la imposibilidad de establecer certezas, propone como solución a la «infradeterminación de las teorías con relación a la evidencia» ${ }^{30}$ la postura que denomina Realismo Subjetivo (o perspectivo), por oposición al Realismo Objetivo (o metafísico). Así, mientras que este último busca conceptos objetivos y absolutos de la realidad y de la verdad, el Realismo Perspectivo no trataría de hallar verdades objetivas, sino que su investigación estaría centrada en procesos generadores de modelos parciales y explicativos de la realidad, existiendo una

29 Popper, K. L., (1992): La sociedad abierta y sus enemigos. Barcelona. Paidós, p. 206.

30 Según la cual, cualquier conjunto de evidencias aparentes que, por definición, no puede ser exhaustivo, es incapaz de determinar lógicamente la explicación teórica de toda realidad, al no poder abarcar en su plenitud dicha evidencia. Siguiendo esta línea de pensamiento, Giere, en su libro Scientific Perspectivism ((2006). Chicago. University of Chicago Press), da una versión del realismo según la cual las descripciones científicas son análogas a los colores, en el sentido de que los sentidos humanos solo capturan aspectos seleccionados de la realidad, debiendo tener en cuenta que estos aspectos, además, no son partes del mundo en sí mismos, sino más bien partes del mundo vistas desde una perspectiva humana. Este «perspectivismo» queda finalmente articulado mediante el recurso a la analogía del uso de mapas y modelos en los procesos de pensamiento. Los mapas representan el mundo, pero la representación que ofrecen es siempre convencional, dada por intereses concretos, por lo que la representación nunca es totalmente exacta ni completa. De la misma manera, los modelos científicos son estructuras idealizadas que representan el mundo desde un punto de vista siempre limitado e imperfecto. 
serie de principios generales que serían la base de dichos modelos parciales o teorías. Las referidas teorías son siempre reflejos incompletos de la realidad, y de ellas sólo se pueden extraer leyes que recojan, no un contenido universal y eterno, sino que se limiten a reflejar la propia realidad contemplada y delimitada por el modelo. Con posterioridad, el científico deberá realizar continuas valoraciones «a posteriori» respecto de cómo su teoría colma o no las expectativas puestas en ella, en relación con la interpretación que da de la realidad, confirmándose o falsándose con las hipótesis o conjeturas efectuadas. Es decir, y siguiendo a Popper, la actitud correcta de un científico es la de, siendo consciente de sus limitaciones, aspirar exclusivamente a obtener aproximaciones a la verdad (abandonando la idea de que la ciencia debe centrarse en el descubrimiento de certezas o verdades absolutas y eternas), a través de la formulación de hipótesis y conjeturas, que deberán estar sometidas continuamente a procesos de crítica (método crítico), a la corrección de errores y a la competencia con otras teorías. Ya que, no siendo posible alcanzar la certeza o «verdad absoluta en si misma», sólo podemos aspirar a tener un conocimiento parcial de lo que percibimos como realidad, y la única vía conocida que nos puede permitir aproximarnos a la verdad es precisamente ese conjunto evolutivo de modelos o teorías mentales incompletas que sí somos capaces de corregir y sustituir, en un intento de superar el mar de incertidumbre en el que nos hallamos inmersos. Desde este punto de vista, el relativismo es un error, pues, aunque no podemos llegar a conocer certezas, si podemos acercarnos cada vez más a la verdad (que por definición es parcial, incompleta y falible), comprobando su concordancia, o no, con los hechos y corrigiendo los errores cometidos. Por ello, la única forma de describir la verdad es precisamente mediante términos «indefinidos» —en el sentido opuesto a las definiciones esencialistas aristotélicas-, y por ese mismo motivo la descripción de normas y de principios generales debe ser formal y su contenido estar sujeto a revisiones, correcciones de errores, cambios y modificaciones, sirviéndonos, no obstante, como guías orientadoras de nuestras acciones.

De esta manera, nos encontramos con que los científicos de la Escuela Austriaca se caracterizan por ser precisamente científicos moderados, partidario de un racionalismo y/o de un escepticismo 
igualmente «moderados» — según las tendencias de cada autorEs decir, conscientes de que la razón es un instrumento básico para el ser humano, pero, al mismo tiempo, aceptando cuales son sus limitaciones. Sabedores de que el hombre, como ser imperfecto, limitado y mortal, no puede llegar a alcanzar el conocimiento de lo absoluto, pero conscientes, al mismo tiempo, de:

a) La existencia de realidades y de límites físicos, químicos y biológicos externos que el hombre debe interpretar de alguna manera,

b) de la posibilidad de que se vayan realizando paulatinas aproximaciones a la verdad, $y$

c) de la existencia de leyes y principios generales de tipo formal, que nos sirven de guía en nuestro continuo proceso de conocimiento de la realidad.

Y siendo, además, partidarios de una especie de realismo subjetivo, que tiene un claro sentido en la creación de modelos y teorías mentales interpretativas, en ese intento de continua aproximación a la verdad - rechazando, de esta manera, tanto el realismo de tipo metafísico, como el relativismo.

\section{$\mathrm{XI}$ \\ LA EPISTEMOLOGÍA EVOLUTIVA DE LA ESCUELA AUSTRÍACA}

Según hemos venido indicando, la epistemología de la Escuela Austriaca se diferencia de otras clases de epistemologías de tipo evolutivo por dos notas características, a las que ya nos hemos referido:

a) En primer lugar, la epistemología austriaca niega la posibilidad de que en las ciencias sociales se puedan elaborar leyes del mismo tipo a las elaboradas en algunas ciencias naturales (física, química), que permitan conocer y determinar con gran exactitud el futuro de los acontecimientos y el devenir. Y, aunque el conocimiento humano cuenta con ciertas «guías» orientadoras, siempre estará limitado por el desconocimiento de lo que el futuro nos depara. 
b) En segundo lugar, y tal y como ya hemos sostenido en otras publicaciones (y esto también es un matiz diferenciador entre la epistemología austriaca y la epistemología poperiana, a pesar de la mucha influencia que esta última tuvo principalmente en Hayek), disminuye la importancia del factor aleatorio en la elaboración de las hipótesis, en lo que al ámbito de las Ciencias Sociales se refiere, ya que la «selección natural» de las conjeturas está previa y fuertemente condicionada por el cúmulo de conocimientos e información previamente acumulados en las instituciones sociales evolutivas, en las normas morales, en la tradición, etc. Es decir, no se descarta el aspecto aleatorio para el establecimiento de hipótesis científicas, pero dentro de ciertos márgenes limitadores. Márgenes que son todavía más condicionantes en las ciencias sociales y, especialmente, en el campo jurídico, económico y político.

No cabe duda de que la interrelación que se da entre todos los elementos que intervienen en el aprendizaje y en la adquisición de nuevo conocimiento es muy difícil de abarcar en su totalidad y, por tanto, resulta muy difícil poder llegar a comprenderla totalmente: El hombre (dotado de percepción, memoria, imaginación y raciocinio) aprende, y gracias al instrumento de la razón - entre otras capacidades adquiridas genéticamente y por evolución culturalelabora hipótesis y conjeturas que van siendo depuradas mediante procesos de prueba y error. A su vez, el nuevo conocimiento influye en la propia evolución de la razón, así como en el entorno donde se desarrolla la acción, creando nuevos escenarios que condicionan la evolución futura, tanto genética como cultural, y así sucesivamente, pues cada nuevo comportamiento puede generar un nuevo entorno, una nueva influencia ambiental que puede generar condicionantes selectivos. Nos encontramos ante un proceso de complejidad extrema y de contenido infinito, donde cada solución a un problema genera, paradójicamente, nuevos problemas e interrogantes por resolver (de ahí la afirmación ya citada de que nuestro conocimiento es finito y nuestra ignorancia es infinita).

Por todo ello, destaca como característica principal de los científicos de la Escuela Austriaca de Economía, al ser conscientes de todo lo expuesto, su prudencia y modestia intelectual, gracias a las 
cuales Menger y Hayek fueron capaces de llegar a identificar la existencia de ordenes espontáneos auto-generados, extensos y de carácter evolutivo, producto de la actividad del hombre, pero que sin embargo superan, por su extensión y complejidad, la capacidad y la percepción de cualquier mente creadora y ordenadora.

XII

CONCLUSIONES

Son muchas las conclusiones que pueden y deben extraerse del presente trabajo. En primer lugar, la necesidad de ser conscientes de que el científico en general, y el científico de las ciencias sociales en particular, deben ser extremadamente prudentes en su trabajo y a la hora de plantear cualquier teoría. Debemos comprender que todas nuestras armas y capacidades para poder adquirir conocimiento (nuestra propia mente, los sentidos, la razón, los leguajes que utilizamos...) son producto de dilatados procesos evolutivos que continúan desarrollándose hoy en día, procesos caracterizados por su extremada complejidad, y de los que es muy posible que jamás podamos tener un conocimiento completo. La mente humana es limitada, al igual que la capacidad racional, y su forma de funcionar implica toda una serie de errores que impiden que pueda llegar a afirmarse que somos capaces de alcanzar conocimientos absolutos, eternos, universales, etc. Por ese motivo, el proceso que nos lleva a la adquisición de conocimiento se ve afectado por todo tipo de imperfecciones y fallos que aparecen ya desde la fase de generación de las sensaciones, y que se extiende hasta alcanzar nuestra capacidad de elaborar conceptos abstractos y el lenguaje. A todo esto debe añadirse la imposibilidad de hacerse con toda la información que, tanto a nivel del actuar de los individuos, como de las instituciones sociales evolutivas, resultaría necesaria para la elaboración de teorías y leyes de certeza universal. Esto lleva a Hayek a considerar — siguiendo aquí las aportaciones efectuadas por Popper y el resto de filósofos defensores de la denominada Epistemología Evolutiva-, que a lo más que podemos aspirar es a acercarnos cada vez más a verdades, que por definición asumen carácter de incompletas, frente a la imposibilidad de alcanzar un conoci- 
miento de lo absoluto, universal e inamovible. Por ello Hayek nos recuerda lo siguiente:

En realidad, el reconocimiento de los límites insuperables de su conocimiento debiera enseñar al estudioso de la sociedad una lección de humildad que lo protegiera en contra de la posibilidad de convertirse en cómplice de la tendencia fatal de los hombres a controlar la sociedad, una tendencia que no sólo los convierte en tiranos de sus semejantes, sino que puede llevarlos a destruir una civilización no diseñada por ningún cerebro, alimentada de los esfuerzos libres de millones de individuos. ${ }^{31}$

No obstante, cabe afirmar que al ser capaces de generar modelos teóricos limitados (modelos a los que venimos denominando como microcosmos), sí que cabría la posibilidad de que dentro de los mismos, y sujetos a sus condicionamientos preestablecidos, podamos dar por sentado (aunque como científicos sepamos que eso es simplemente una licencia falsa que simplemente nos permite, $o$ facilita, el desarrollo y aplicación de nuestros modelos) que dentro de los mismos existen determinadas certezas, que, evidentemente no lo son si se refieren a modelos superiores que los integren y que dispongan de mayor información, o que resulten más explicativos que los anteriores, sin tener por ello que anularlos o refutarlos por completo. Lo mismo sucede cuando hablamos de certezas respecto de desarrollos de lenguajes formales (que, como cualquier otro tipo de lenguaje son, simplemente, un sistemas de signos y las reglas establecidas para manipularlos y combinarlos) como es el caso del leguaje matemático o de la lógica (del tipo que sean), ya que en realidad se trata de elaboraciones de nuestras mentes, por lo que son reflejo de las mismas, con todas sus limitaciones fuera del propio microcosmos que supone la mente humana y que, evidentemente, están sujetos a las limitaciones que ello conlleva, y a las definiciones y los convencionalismos preestablecidos que los sustentan. Sólo así podrían entenderse como certezas, es decir, dentro del propio sistema que generan. Sin embargo, no debe olvidarse

${ }^{31}$ Traducción del discurso de aceptación del Premio Nobel de Economía de F. A. Hayek, publicado por el Cato Institute (www.elcato.org). 
que se trata siempre de una licencia que debe utilizarse con suma cautela, debiendo tener en cuenta, además, que cualquier sistema matemático o lógico de conocimiento es incompleto por definición (Teoremas de la Incompletitud de Gödel, a los que ya nos hemos referido, etc.). Por otra parte, todo leguaje formal siempre dependerá de la verdad, la falsedad, la corrección, etc., de las proposiciones que se tomen como «axiomas» a la hora de utilizarlos en los razonamientos que se lleven a cabo, y que en definitiva dichos axiomas no dejan de ser proposiciones, es decir, teorías o hipótesis, y que por ello sólo pueden tenerse, como tales axiomas, referidos al correspondiente modelo ${ }^{32}$.

Por suerte, esta postura científica que viene siendo denominada Racionalismo moderado o crítico, está siendo cada vez más y más aceptado por la comunidad científica a todos los niveles, y no ya sólo por los pensadores partidarios de la Epistemología evolutiva encabezados por Hayek y Popper, sino que ya muchos científicos de las ciencias naturales, como es el caso del físico teórico Stephen Hawking, no dudan en afirmar que los modelos utilizados por los científicos no es posible que tengan en cuenta todas las pequeñas variables, y que las mismas podrían tener importantes consecuencias desconocidas. Afirmando, además, que plantearse si existe «la realidad», como tal, es algo inalcanzable para nuestra mente, ya que es nuestra propia mente la que crea todos nuestros modelos, siendo uno de ellos el propio modelo «tridimensional» del exterior que nos rodea y que encaja en lo que llamamos «la realidad». Ese modelo de la realidad incluiría también nuestras emociones y nuestras sensaciones, así como el significado que les atribuimos, y dichos significados sólo existen dentro de las fronteras de nuestra limitada mente humana. De esa manera, debemos aceptar los límites de lo que podemos saber, aceptando, por ello, los modelos de «nuestra» realidad que sean más adecuados en función de su capacidad para ser más explicativos y con menos errores, es decir, más verdaderos hasta ese momento. Debiendo tener siempre en cuenta, tal y como nos recuerda Popper, que:

${ }^{32}$ Como sería el caso del denominado axioma de la acción humana de la propia Escuela Austriaca, que fue elaborado por L. von Mises a partir de los estudios previos de Carl Menger. 
La creencia en la certeza científica y en la autoridad de la ciencia no pasa de ser un piadoso deseo: la ciencia es falible porque es humana. ${ }^{33}$

No cabe duda de que Hayek, que sin duda es uno de los más destacados autores de la Escuela Austríaca de Economía, es además uno de los principal representante del Racionalismo moderado y de la Epistemología evolutiva en las ciencias sociales, y sus aportaciones en este campo del saber (desde múltiples disciplinas: filosofía, psicología, antropología, historia, economía, derecho, estudio de los órdenes espontáneos, etc.), son de un valor incalculable, al haber abierto nuevas perspectivas y vías para la investigación científica del futuro.

\section{REFERENCIAS BIBLIOGRÁFICAS}

Alston, V. P. (1985):) Filosofía del lenguaje. Madrid. Alianza.

Agustí, J., Bufill, E., Mosquera, M. (2012): El precio de la inteligencia. Barcelona. Editorial Crítica.

Arsuaga, J. L. y Martínez, I. (2004): Atapuerca y la evolución humana.

Barcelona. Fundación Caixa Catalunya.

Bajo Molina, $\mathrm{M}^{\mathrm{a}}$ T. (2016): Mente y cerebro. Alianza Editorial.

BAUR, M. y ZIEGLER, G. (2003): La aventura del hombre: todo empezó en África. Edit. Nueva.

BRÉHIER, E. (1988): Historia de la filosofía. 2 vols. Madrid. Tecnos.

Calvo I TRIas, M. (2002): Útiles líticos prehistóricos: forma, función y uso. Editorial Ariel.

CANFORA, L. (2003): Aproximación a la historia griega. Alianza Editorial.

Castells, M., e Ipola, E. (1975): Metodología y epistemología de las ciencias sociales. Madrid. Ayuso.

CAstro, L., y Toro, M. A. (1995): «Human Evolution and the Capacity to Categorize», Journal of Social and Evolutionary Systems, n. 18 , pp 55-66.

33 Antiseri, D., (2002): Kark Popper, protagonista del siglo xx. Madrid. Unión Editorial - Instituto de Estudios Económicos, p. 9. 
- (1998): «The Long and Winding Road to the Ethical Capacity». History and Philosophy of the Life Sciences, vol. 20, pp. 77-92.

- (2002): «Cultural Transmision and the Capacity to Approve or Disapprove of Offspring's Behaviour». Journal of Memetics, n. ${ }^{\circ}$ 6.

- (2004): «The evolution of Culture. From Primate Social Learning to Human Culture». Procedings of the National Academy of Sciences, vol. 101, pp. 10235-10240.

- (2002). «La evolución del lenguaje». Diálogo Filosófico 53, 275290.

Castro, L., Castro, M. Á. y Morales, J. (2005): Metodología de las ciencias sociales (Una introducción crítica). Madrid. Tecnos.

CopI, I. (1973): Introducción a la lógica. Buenos aires. Eudeba.

Chalmers, A. F. (1990): ¿Qué es esa cosa llamada ciencia? Madrid. Siglo XXI.

Сномsку, N. (1982): La explicación en las ciencias de la conducta. Madrid. Alianza.

DAMASIO, A. (2010): El error de Descartes: la emoción, la razón y el cerebro humano. Editorial Crítica.

DARIO, A. (2002): Karl Popper, protagonista del siglo Xx. Madrid. Unión Editorial e Instituto de Estudios Económicos.

DAWKINS, R. (2002): El gen egoísta: las bases biológicas de nuestra conducta. Barcelona. Salvat.

DeACON, T. W. (1997): «What makes the human brain different?». Annu. Rev. Anthropol. 26: 337-57.

DANCY, J. (1993): Introducción a la epistemología contemporánea. Madrid. Tecnos.

DARWIN, C. (1982): El Origen del Hombre. Madrid. Edaf. (1980): El Origen de las Especies. Madrid. Edaf.

EKELUND, R. B. J.R. y HeberT, R. F. (1995): Historia de la Teoría Económica y su Método. Madrid. McGraw-Hill.

Escudero, J. A. (1986): Curso de la Historia del Derecho. Madrid. Graficas Solana.

Feyerabend, P. (1982): La ciencia en una sociedad libre. Madrid. Siglo XXI.

- (1992): Tratado contra el Método. Esquema de una Teoría Anarquista del Conocimiento. Madrid. Tecnos.

- (2000): La conquista de la abundancia .Barcelona. Paidós. 
- y Naess, A. (1979): El mito de la ciencia y su papel en la sociedad. Valencia. Cuadernos Teorema.

Fontdevila, A. y Moya, A. (2003): Evolución: origen, adaptación y divergencias de las especies. Síntesis.

Fuster, J. M. (2013): The Neuroscience of Freedom and Cerativity. Cambridge.

- (2003): Cortex and Mind: Unifying Cognition. Nueva York. Oxford University Press.

Geary, D. C. El origen de la mente. Evolución del cerebro, cognición e inteligencia. Manual Moderno.

GOWLETT, J. (1999): Arqueología de las primeras culturas: los albores de la humanidad. Ediciones Folio.

Grube, G. (1973): El pensamiento de Platón. Madrid. Gredos.

Hartnack, J. (1988): La Teoría del conocimiento de Kant. Madrid. Cátedra.

HAYEK, F. A. Derecho, Legislación y Libertad. Madrid. Unión Editorial.

- (1990): La Fatal Arrogancia (Los Errores del Socialismo). Madrid. Unión Editorial.

- La Contrarrevolución de la Ciencia. Colección: Biblioteca Austriaca. Madrid. Unión Editorial.

- (2011): El orden sensorial. Madrid. Unión Editorial.

- (2013): Nuevos estudios de filosofía, política, economía e historia de las ideas. Madrid. Unión Editorial.

- (2013): Estudios de filosofía, política y economía. Madrid. Unión Editorial.

Huerta de Soto, J. (1992): Socialismo, Cálculo Económico y Función Empresarial. Colección: Nueva Biblioteca de la Libertad, vol.1. Madrid. Unión Editorial.

Hume, D., Ensayos Políticos. Madrid. Unión Editorial.

- (1988): Tratado de la Naturaleza Humana. Madrid. Tecnos.

- (1980): Investigación sobre el Entendimiento Humano. Madrid. Editorial Alianza.

Iglesias, J. (1986): Derecho Romano. Instituciones de Derecho Privado. Barcelona. Ariel.

Infantino, L: El Orden sin Plan. Madrid. Unión Editorial.

KANDEL, E. (2007): En busca de la memoria: el nacimiento de una nueva ciencia de la mente. Katz.

KANT, I. (1995): Crítica de la razón pura. Madrid. Alfaguara. 
- (1995): Crítica de la razón práctica. Sígueme.

- (1995): Crítica del juicio. Madrid. Espasa Calpe.

- (1959): Prolegómenos. Madrid. Aguilar.

- (1956): Fundamentación de la metafísica de las costumbres. Madrid. Espasa Calpe.

KöRNER, S. (1977): Kant. Madrid. Alianza Universidad.

Kunn, T. S. (1990): La Estructura de las Revoluciones Científicas. México. FCE.

LAKATOS, I. (2001): Historia de la Ciencia y sus reconstrucciones racionales. Madrid. Techos.

- (1998): La metodología de los programas de investigación científica. Madrid. Alianza.

Lamarck (Jean Baptiste de Monet, Caballero de Lamarck) (1986): Filosofía Zoológica. Barcelona. Alta Fulla.

LeONI, B. (1995): La Libertad y la Ley. $2^{\text {a }}$ Edición ampliada. Madrid. Unión Editorial.

LEWIN, R. (2000): Evolución humana : la más amplia perspectiva acerca de los orígenes de la Humanidad. Barcelona. Salvat Editores.

Macdonald Durbar, R. I. (1996): The Trouble with Science. Harvar University Press.

Marcuse, H. (1995): Razón y evolución: Hegel y el surgimiento de la Teoría social. Madrid. Alianza.

Martinez Meseguer, C. (2009): La Teoría evolutiva de las instituciones (la perspectiva austriaca). Segunda Edición. Madrid. Unión Editorial.

Menger, C. (1983): Principios de Economía Política. Madrid. Unión Editorial.

- (1996): Sul metodo delle Scienze Sociali, Leberilibri di AMA srlMaceram.

Mises, L. V. (1986): La Acción Humana (Tratado de Economía). Madrid. Unión Editorial.

- (2003): Teoría e Historia. Madrid. Unión Editorial.

- (2013): Problemas epistemológicos de la economía. Madrid. Unión Editorial.

Morgenstern, O. (1970): Sobre la Exactitud de las Observaciones Económicas. Madrid. Tecnos.

PINKER, S. (1994): The Language Instinct. New York. William Morrow and Company. 
Popper, K. L. (1992): La Sociedad Abierta y sus Enemigos. Barcelona. Paidós.

- (1994): En Busca de un Mundo Mejor. Barcelona. Paidós.

- (1973): La Lógica de la Investigación Científica. Tecnos, Madrid.

- (1995): La Miseria del Historicismo. Madrid. Alianza.

- (1994): Conjeturas y Refutaciones: El Desarrollo del Conocimiento Científico. Barcelona. Paidós. Barcelona.

- (1985): Búsqueda sin Término. Una Biografía Intelectual. Madrid. Tecnos.

PotTer, J. (1998): La representación de la realidad. Barcelona. Paidós.

RADNITZKY, G., BARTLEY, W. W. y otros. (1993): Evolutionary Epistemology, Rationality, and the Sociology of Knowledge. Editores: Radnitzky y Bartley.

Russell, B. (1964): El conocimiento humano, su alcance y sus límites. Madrid. Taurus.

Tomasello, M. (1999): The Cultural Origins of Human Cognition. Harvard University Press.

VV.AA. (1997): El lenguaje humano. Colección Temas (n. ${ }^{\circ}$ 5). Investigación y Ciencia (Scientific American). Prensa Científica.

VV.AA., Epistemología evolucionista. Paidós.

VV.AA. (2003): Los orígenes del hombre: de los primeros homínidos al homo sapiens. National Geographic.

Williams, G. C. (1966): Adaptation and Natural Selection. Priceton.

ZanotTI, Gabriel J. Introducción Filosófica al Pensamiento de Friedrich A. Hayek. Colección: Biblioteca Austriaca. Madrid. Unión Editorial. 
